\title{
Telic senses of deadjectival verbs
}

\author{
Kate Kearns* \\ Department of Linguistics, University of Canterbury, Private Bag 4800, \\ Christchurch, New Zealand
}

Received 12 May 2004; received in revised form 30 July 2005; accepted 3 September 2005

Available online 13 October 2005

\begin{abstract}
In this paper I address two main issues in the semantics of deadjectival verbs. First, I review alternative accounts of the nature of the telos associated with a deadjectival verb on a telic interpretation. Traditional accounts gloss the telic sense of a deadjectival verb as 'become A': for example, the telic interpretation of The sky cleared is 'The sky became clear'. On this account, the telos of the event denoted by telic clear is the onset of the state denoted by The sky is clear. An alternative account by Hay et al. (1999) is based on the property scale associated with an adjective and its derived verb. Property scales may be open, with no maximal degree of the property (i.e. no upper bound), or closed, in which case the property has a maximal possible degree beyond which no higher degrees of the property exist, and the maximal degree of the property constitutes the upper bound of the scale. Hay et al. argue that a telic interpretation arises where a deadjectival verb is interpreted with reference to a closed property scale. In the event denoted by a telic deadjectival verb, the theme of change traverses the property scale to the upper bound, the maximal possible degree of the property. For example, in The sky cleared on a telic interpretation, the sky is understood to traverse the scale of increasing degrees of clearness until the maximum possible degree of clearness is reached. On this account, the telos is the onset of the state in which the sky is maximally clear, such that it could not be clearer. I argue in favour of the traditional view that a telic deadjectival verb denotes 'become A', and against the alternative account that a telic deadjectival verb denotes 'become maximally A'.

By way of clarification preparatory to the main discussion, I show that deadjectival verbs have two types of telic sense, an achievement sense and an accomplishment sense. The telic sense at issue in the traditional telic/atelic contrast is the accomplishment sense.

I also argue that the availability of telic and atelic senses of deadjectival verbs is generally predictable from characteristics of the state denoted by $x$ is A. The telic (accomplishment) sense of a deadjectival verb is available only if the property region that counts as ' $A$ ' has a lower bound (i.e. the least degree that counts as ' $\mathrm{A}$ ') which is accessible to modification. The telic (accomplishment) sense is
\end{abstract}

* Tel.: +64 3 3642632; fax: +64 33642969 .

E-mail address: kate.kearns@canterbury.ac.nz. 
the strong default reading where $x$ is $A$ entails that $\mathrm{x}$ bears the maximal possible degree of the relevant property.

(C) 2005 Elsevier B.V. All rights reserved.

Keywords: Deadjectival verbs; Open- and closed-scale adjectives; Diagnostics for telicity; Telicity alternations; Accomplishments; Achievements; Resultatives

\section{Introduction}

This paper addresses two main issues in the semantics of deadjectival change-of-state verbs:

(a) the nature of the telos of the event denoted by a deadjectival verb on a telic interpretation; (b) the prediction of the availability of telic and atelic interpretations for these verbs.

As a necessary background to discussion of these issues, I shall also show that degree achievement verbs (Dowty, 1979:88), including many deadjectival verbs, have two types of telic sense. On the first telic sense the verb denotes a single transition to an endstate which is defined only by comparison to the prior state of the theme argument: this is the 'become A-er' sense, and is a Vendlerian achievement. ${ }^{1}$ The atelic sense of a deadjectival verb denotes a process consisting of iterated 'become A-er' achievement events. On the second telic sense a deadjectival verb denotes a durative event which is terminated by the onset of a uniquely specified endstate. I shall argue that this is the 'become A' sense, and is a Vendlerian accomplishment. In the main discussion of this paper and in the previous literature, the atelic senses of deadjectival verbs are processes, and the telic senses at issue are accomplishments, not the 'become A-er' achievement sense.

Accordingly, the two main issues identified above are more accurately stated as follows:

(a) the nature of the telos of the event denoted by a deadjectival verb on an accomplishment interpretation;

(b) the prediction of the availability of process and accomplishment senses of deadjectival verbs.

Before introducing issues (a) and (b) in more detail, I outline my preliminary assumptions concerning the semantics of adjectives and deadjectival verbs. ${ }^{2}$

Where $\mathrm{V}$ is a change-of-state verb derived from an adjective $\mathrm{A}$, any interpretation of $x$ V-ed entails ' $x$ became A-er'. It may or may not also entail 'x became A' or 'x became maximally A', but ' $\mathrm{x}$ became A-er' is always entailed. Accordingly, the notion of comparison is basic to the

\footnotetext{
${ }^{1}$ The terms accomplishment and achievement are used here according to Vendler's (1967) classification based on the temporal properties of events, in contrast with the more thematic classification of Dowty (1979). A Vendlerian achievement is conceived of as momentary, and is canonically a transition to a state (see Piñón (1997) for discussion. An accomplishment is a process terminated by a finishing point which is expressed in the predicate.

Dowty defines achievements in terms of the BECOME operator, which subsumes all changes of state both momentary and durative, bounded and unbounded. He defines accomplishments as of the form CAUSE BECOME, thus coding the difference between achievements and accomplishments thematically, in terms of causation, and not in terms of temporal properties of the event. For Dowty, the causative/inchoative alternation is an alternation between accomplishments and achievements, regardless of the presence or absence of bounding and duration. For criticism and discussion see Levin (2000).

${ }^{2}$ I assume below a simplified account of the semantics of adjectives and deadjectival verbs in terms of property scales. For a detailed discussion and analysis, see Kennedy (1999) and references cited there.
} 
interpretation of deadjectival verbs, and deadjectival verbs, like comparative adjectives, are generally considered to be interpreted with reference to a property scale consisting of ordered degrees of the relevant property. A comparative adjective is interpreted in terms of the relative positions of two points on a property scale. A deadjectival verb is interpreted in terms of movement along a property scale. These notions are illustrated in (1).

(1) a. $x$ is cooler than $y$.

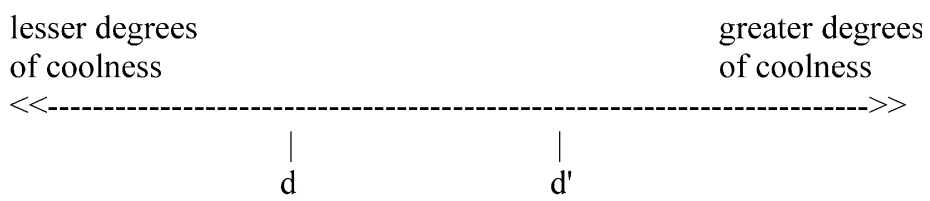

$y$ bears the property of coolness to degree $d$

$x$ bears the property of coolness to degree $d^{\prime}$

$\mathrm{d}<\mathrm{d}^{\prime}$

b. $x$ cooled.

$\begin{array}{lll}\begin{array}{l}\text { lesser degrees } \\ \text { of coolness }\end{array} & \begin{array}{l}\text { greater degrees } \\ \text { of coolness }\end{array} \\ <<--1 & \left.\right|^{\prime} & \\ & d & d^{\prime}\end{array}$

$\mathrm{x}$ bears the property of coolness to degree $\mathrm{d}$ at time $\mathrm{t}$

$\mathrm{x}$ bears the property of coolness to degree $\mathrm{d}^{\prime}$ at time $\mathrm{t}^{\prime}$

$\mathrm{t}<\mathrm{t}^{\prime} \& \mathrm{~d}<\mathrm{d}^{\prime}$

The interpretation of $x$ is cooler than $y$ or $x$ cooled may relate two points on any part of the scale, without any commitment to the truth of $x$ is cool or $y$ is cool: there is no contradiction in saying Both $x$ and $y$ are extremely hot, but $x$ is cooler than $y$, or $x$ has cooled but is still very hot. I shall assume that there is a root element cool which denotes the whole property scale of degrees of temperature as in (2), and from which adjectives and verbs are both derived.

property scale denoted by [Root $\mathrm{Cool}]$

lesser degrees

of coolness greater degrees

of coolness 
In contrast, the positive form of the adjective cool is interpreted with reference to a region on the property scale which is determined by a complex interplay of contextual factors, including expected norms for the property as borne by particular kinds of theme. For example, cool soup may be at room temperature or above, but a cool drink is below room temperature. I shall call the contextually determined region of values associated with the positive form of an adjective the standard value. The standard values denoted by the adjective [Adj $\mathrm{cool}$ ] in different collocations are illustrated in (3).

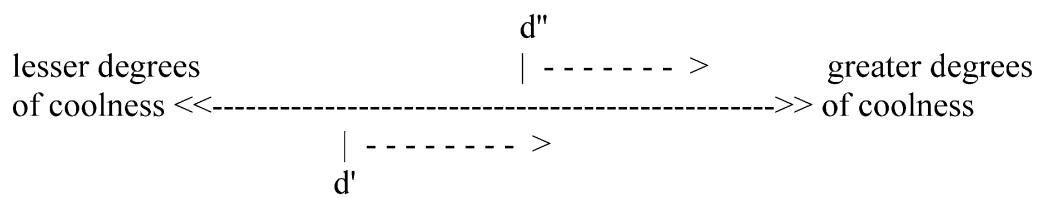

The soup is cool is true iff the soup bears the property of coolness to degree d, where $\mathrm{d} \geq \mathrm{d}$ ".

The beer is cool is true iff the beer bears the property of coolness to degree $\mathrm{d}^{*}$, where $\mathrm{d}^{*} \geq \mathrm{d}^{\prime}$.

I draw a distinction between the root element cool, denoting the property scale, and the positive adjective cool, denoting a region on the property scale. Strictly speaking, both the verbs described as deadjectival and the positive form of the associated adjective are derived from the root, and the verb is not directly derived from the surface adjective. With this proviso, I shall continue to use the term deadjectival verb to refer to verbs whose base also surfaces as an adjective.

I return now to outlining the two main issues of the paper, first, the nature of the telos of a telic (i.e. accomplishment) deadjectival verb, and second, predicting the availability of telic (accomplishment) and atelic (process) senses of deadjectival verbs.

Theories of deadjectival verbs (cool, harden, empty, clear, etc.) make different predictions concerning the nature of the telos of an event denoted by the verb on an accomplishment reading. The main points at issue are outlined here, and more detailed discussion is given in section 3 .

Abusch (1986) describes the sense of an atelic deadjectival verb as 'become A-er', and the sense of a telic deadjectival verb as 'become A'. The same kind of telos for the telic sense is described in Levin and Rappaport Hovav (1991:129-130) and in Jackendoff (1996:331), where change of state is described as movement along a path constituted of degrees of a property, such as hotness, flatness, or size. ${ }^{3}$ Jackendoff writes: 'If the "path" has a boundary (reaching hot or flat) the sentence is telic. If the "path" is nonbounded (going on indefinitely in the "hotwise" or "bigwise" direction), the sentence is atelic'.

In the kind of endstate described here for the telic senses, the degree of the property borne by the theme at the end of the event is determined by the interpretation of the positive adjective $A$, collocated with the same argument as the verb, and evaluated on the same contextually appropriate norm-referencing. I shall refer to this endstate as the standard endstate. Where the

\footnotetext{
${ }^{3}$ For change of state as traversal of a property scale, see also Filip (1999:106-108) and Wechsler (1995:49), among others.
} 
onset of the standard endstate constitutes a telos, I shall call this point the standard telos. The analysis is diagrammed in (4).

$x$ verbed.

$\mathrm{d}^{\prime}=$ lower bound of standard value for $A$ in context

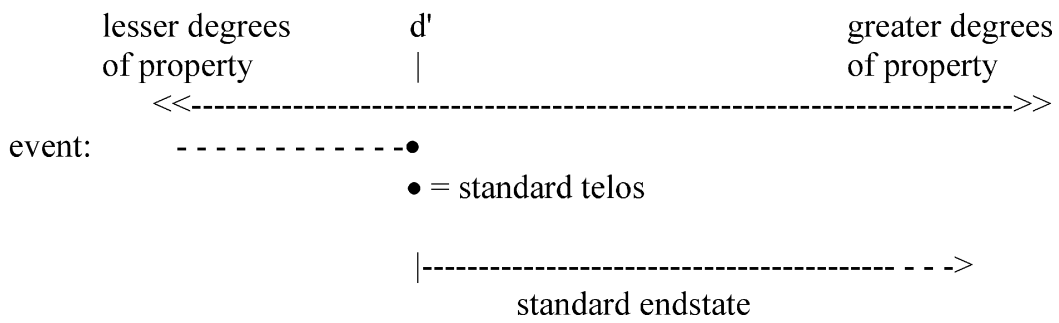

More recently, Hay et al. (1999) offer an account of telic deadjectival verbs which is not primarily based on the attainment of an endstate (i.e. become $(\varphi)$ ), but based on the traversal of the property scale involved in the interpretation of the associated adjective. If the property scale has an upper bound, comprising the maximum possible degree of the relevant property (relativised to the argument and context), then the derived verb carries an implicature of totality, according to which the property scale is fully traversed in the event, and thus the degree of change is bounded. The predicate has a telic (i.e. accomplishment) reading, and the telos of the event is the onset of the state in which the theme argument bears the maximal value of the relevant property, relativised to the argument and context. I shall refer to the maximal property value endstate as the maximal endstate, the onset of which provides a maximal telos.

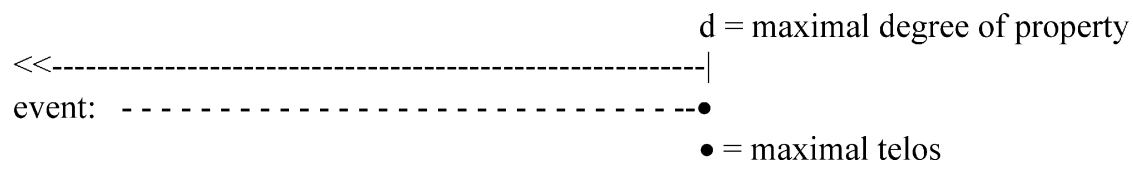

I shall argue in favour of the standard telos account and against the maximal telos account of the accomplishment senses of deadjectival verbs.

The second main issue to be addressed is the prediction of the availability of telic (accomplishment) and atelic (process) senses for deadjectival verbs. Hay et al. argue that the availability of atelic (process) and telic (accomplishment) senses of deadjectival verbs is predicted by the nature of the relevant property scale interacting with a quantity implicature of 'completeness'. Briefly, if the scale has an upper bound, which is that maximal value of the property in question beyond which higher values are not possible, then quantity implicature gives rise to the telic (accomplishment) interpretation that the scale was completely traversed and the maximal endstate was reached, the onset providing the telos. The quantity implicature can be cancelled by explicit modification with but not completely or for $x$ time, in which case the verb has an atelic interpretation.

If the scale has no upper bound, then complete traversal of the scale is not possible and no telos is available. The default interpretation is atelic (process). However, an otherwise unbounded 
scale may be understood to have a normative upper bound in specific collocations and contexts, in which case a telic sense is available.

I shall identify difficulties with this account, and argue instead that the availability of process and accomplishment senses of deadjectival verbs is largely predictable from the denotation of $x$ is $A$ :

(i) A positive adjective such as wide denotes a property region (i.e. the standard value) with a lower bound which is partly inaccessible to modification, and this correlates with the lack of an accomplishment sense for the derived verbs.

(ii) A positive adjective like clear, which lexicalises a maximal value, is associated with a verb with a default accomplishment sense. Process senses for these verbs (in the non-progressive) are also possible.

(iii) A root like dark denotes a closed property scale (the upper bound of dark is the complete absence of light), but the positive adjective dark does not lexicalise the maximal value (that is, the standard value and maximal value for dark may differ). Verbs associated with adjectives of this type take both process and accomplishment senses freely. These are included in the group identified by Dowty (1979:88) as degree achievements. ${ }^{4}$

The paper is structured as follows. In section 2 I shall review two types of bounded event denoted by degree achievements, including many deadjectival verbs, which I identify as achievements and accomplishments. I shall argue that the central criterion which identifies the accomplishment sense of a deadjectival verb (the intended telic sense in the literature on deadjectival verbs) is that the telos is the onset of a specified unique endstate, which I identify as the standard endstate defined above. The standard endstate for deadjectival accomplishment verbs is discussed further in section 3, where I review in more detail Hay et al.'s predictions concerning the maximal nature of the telos with deadjectival verbs, and discuss problems for their account. I show that the standard telos account is preferable for verbs associated with both open and closed property scales, and conclude that the nature of the telos is not provided by the upper bound of a property scale, but by the standard value denoted by $x$ is $A$.

In section $4 \mathrm{I}$ address the second main issue, that of predicting the availability of process and accomplishment senses. I contrast Hay et al.'s account, in terms of the closed or open nature of the relevant property scale, with my account in terms of the denotation of $x$ is $A$. I identify difficulties with Hay et al.'s theory in predicting which verbs may alternate in telicity and which may not, and argue that the nature of the denotation of $x$ is $A$ has greater predictive value. I conclude that the implicature which gives rise to accomplishment interpretations is ' $\mathrm{x}$ becomes A', not the implicature proposed by Hay et al. that the theme traverses the property scale 'completely', to an upper bound. I also address a further issue arising from the assumption (which I share with Hay et al.) that the basic sense of deadjectival verbs is 'become A-er', elsewhere identified as atelic, and the accomplishment sense arises by implicature. This assumption seems inconsistent with the observation that the 'become A-er' sense, assumed to be basic, appears to be

\footnotetext{
${ }^{4}$ After Dowty, the term degree achievements is commonly applied to gradual change-of-state verbs which are modifiable by both in and for adverbials. The term reflects the covertly thematic nature of Dowty's analysis of verb classes, and is not compatible with the Vendler aspectual classes, which I assume in this paper. Dowty's main discussion of degree achievements concerns the semantics of the durative unbounded sense, modifiable by a for adverbial, as in The soup cooled for ten minutes. Because the predicate here denotes a change of state, it is based on the BECOME operator and is an achievement in Dowty's classification, although it is a process in Vendler's classification.
} 
absent for some deadjectival verbs. I show that the 'become A-er' (process) sense is possible for these verbs in certain contexts. Conclusions are given in section 5.

\section{Endstates and telê}

As introduced in the previous section, the main issues to be discussed in this paper concern what are generally termed the telic and atelic senses of deadjectival verbs. However, in discussions of telic/atelic contrasts, deadjectival verbs present special problems because in fact deadjectival verbs have two different types of telic sense.

Note first that all senses of deadjectival verbs express at least the change of state expressed by 'become A-er': an endstate characterised in this way is entailed by all aspectual senses of a deadjectival verb, including the process sense identified by Abusch (1986) as atelic. The most minimal event denoted by The soup cooled, whether considered as a separate event, as part of an unbounded process, or as part of a culminated process, or accomplishment, results in a state in which the soup is cooler than it had been. This is a kind of endstate which I shall call the comparative endstate. As we shall see, the onset of this endstate is a kind of telos.

A predicate which lexically entails an endstate is generally classed as telic, and accordingly we might conclude that deadjectival verbs are always telic, because they always entail a comparative endstate. Bertinetto and Squartini (1995:13-14) adopt this conclusion: observing that comparative endstates occur in telic predicates, such as The temperature got colder in ten minutes, Bertinetto and Squartini claim that change-of-state process verbs (their 'gradual completion verbs', Dowty's 'degree achievements') are always telic.

I shall review traditional tests for telicity, and evidence for the telicity of the comparative endstate. I shall identify two telic senses for gradual change-of-state verbs (including many deadjectival verbs): achievements and accomplishments. The main finding from this section to be carried forward is that the two senses of deadjectival verbs at issue in this paper and in the previous literature, commonly identified as atelic and telic, are the process and accomplishment senses. The achievement sense of a deadjectival verb, with a comparative endstate, is not included in the main discussion of telic senses, even though it is demonstrably a telic sense.

\subsection{In adverbials, the take time construction, and comparative endstates}

First, I clarify certain points concerning the use of in adverbials and the take time construction as telicity diagnostics.

The simple acceptability of an in adverbial is not enough in itself to show that the modified predicate is telic. First, all aktionsart types of predicate freely take in adverbials in the future tense, as in (6), with an 'event delay' reading; that is, the adverbial denotes an interval which elapses before the event occurs or begins.
a. We will drive to town in ten minutes.
(accomplishment)
'Ten minutes from now we will begin driving to town.'
b. He will reach the summit in an hour.
(achievement)
'At the end of an hour from now he will reach the summit.'
c. The room will be dark in an hour.
(state)
'At the end of an hour from now the room will be dark.'
d. We will open gifts in half an hour.
(process)
'At the end of half an hour from now we will begin opening gifts.' 
In addition, state predicates in the past tense take in adverbials with the event delay reading, as in (7).

(7) a. John was at the summit in an hour.

'At the end of an hour John was at the summit.'

b. The meal was ready in a few minutes.

'After a few minutes the meal was ready.'

The event delay reading does not signal that the modified predicate is telic-rather, on the event delay reading the delay period itself, before the event occurs, is bounded. The two interpretations, which signal that the modified predicate is telic, are the whole event duration reading, characteristic of accomplishments, and the whole event delay reading, characteristic of achievements. An accomplishment predicate may be modified by an in adverbial or the take time construction as in (8), with the event duration reading; the adverbial gives the duration of the whole event.

a. John wrote the letter in ten minutes.

b. It took John ten minutes to write the letter.

'John wrote the letter, and the whole letter-writing event had a duration of ten minutes.'

With an achievement predicate, an in adverbial or the take time construction expresses the delay before the whole event occurs, as in (9).

a. John reached the summit in an hour.

b. It took John an hour to reach the summit.

'At the end of an hour John reached the summit.'

Filip (1999:22) distinguishes between the duration and delay readings by the entailment from ' $\mathrm{x}$ verbed in an hour' to ' $x$ was verbing during that hour', found only with accomplishments. I note that the intended entailment found with accomplishments is more clearly expressed as ' $\mathrm{x}$ was verbing throughout that hour', which excludes the reading 'at some point during that hour, $\mathrm{x}$ was verbing'. The same distinction applies to the take time construction: 'It took an hour for $\mathrm{x}$ to verb' entails ' $\mathrm{x}$ was verbing throughout that hour' only if the predicate is an accomplishment. The diagnostic applies to the examples in (9); John reached the summit in an hour does not entail 'John was reaching the summit throughout that hour'.

Process predicates in the past tense are generally judged to be anomalous with both in adverbials and the take time construction, though an event delay reading may be understood. This is illustrated in (10).

a. It took an hour for them to chat.

b They chatted in an hour.

\# 'They chatted, and the chatting event had a duration of an hour.'

?? 'After an hour they (finally) began to chat.'

The anomaly of examples like (10), in contrast to (9), allows us to distinguish achievements and processes, though the adverbial may be assigned the event delay reading in both kinds of example. Accomplishments are identified by the event duration reading. 
Gradual change-of-state verbs such as increase and decrease have only the comparative endstate readings 'become more' and 'become less', which are traditionally considered to be atelic. With verbs of this type an in adverbial or take time construction is well-formed, and has the event delay reading, illustrated in (11).

a. The price increased/decreased in a month.

b. It took a month for the price to increase/decrease.

'After a month had passed the price increased/decreased.'

Note that neither (11a) nor (11b) entails 'The price was increasing/decreasing throughout that month', and accordingly increase/decrease here are not accomplishments. As we saw in (10), an in adverbial is anomalous with past tense processes, so the acceptability of (11) indicates that increase and decrease here are not processes. I conclude that these are Vendlerian achievements, denoting a single transition 'become more/less', 5 with a comparative endstate. ${ }^{6}$ I assume that the process interpretation of verbs of this type as in The price increased for a month is of a series of iterated 'become more' achievements (see Dowty, 1979:88-90 for a similar account).

Turning now to deadjectival predicates, we see that widen in $(12 \mathrm{a}, \mathrm{b})$ below has only the event delay reading with an in adverbial- $(12 \mathrm{a}, \mathrm{b})$ do not entail 'The gap was widening throughout those few minutes'. Widen also has only the comparative endstate, as (12a,b) entail 'The gap was wider', but not 'The gap was wide'. Accordingly, widen in $(12 \mathrm{a}, \mathrm{b})$ is an achievement predicate of the same type as increase/decrease in (11).

a. The gap widened in a few minutes.

b. It took a few minutes for the gap to widen.

'After a few minutes had passed the gap widened."

To sum up this section, we see that gradual change-of-state verbs such as increase and widen are classed as telic according to in adverbials and the take time construction. The verbs entail only the comparative endstate, and the telicity-sensitive adverbials have the event delay reading characteristic of Vendlerian achievements.

\subsection{Comparative endstates, for adverbials and the present perfect}

The telicity of 'become A-er' predicates is also supported by for adverbials modifying the duration of a result state, as illustrated in (13).

\footnotetext{
5 I consider that scalar implicature (cf. Grice's (1975) Quantity 1; Horn's (1984) Q-implicature) provides the inference that further transitions did not occur.

${ }^{6}$ As noted above, Bertinetto and Squartini (1995:14) argue that a change of state verb with a comparative endstate is telic because of the acceptability of In ten minutes, the temperature got colder. I point out that this example must have the event delay reading, indicating an achievement.

${ }^{7}$ An anonymous reviewer finds (12a) and (12b) acceptable on the event duration reading, with (12b) a little better than (12a). Judgments seem to vary here. A contextual limit on the gap-widening event may improve the example for some speakers. Suppose that a gap in the rocks is actually a mechanised secret entrance to the Oregon MIB headquarters, and that when the mechanism is activated, the gap widens slowly to its fullest extent, which admits large vehicles. Here the increasing width of the gap is incremental and upper-bounded. To my judgment, (12a,b) are still awkward in this context on an accomplishment interpretation.
} 

a. $\quad$ The pressure increased for a few minutes.
'(Having increased), the pressure was greater for a few minutes.'
b. The gap widened for a few minutes.
'(Having widened), the gap was wider for a few minutes.'

The presence of a result state reading for a for adverbial is not usually cited as a diagnostic for telicity, although Pustejovsky (1995:74) identifies predicates with result state for adverbials as telic. Piñón (1999) points out that processes and states lack result states-events with result states are accomplishments or achievements, and thus denoted by telic predicates on traditional assumptions. The result state adverbials in (13), then, support the claim that comparative endstate senses are telic.

The acceptability of the non-progressive present perfect with deadjectival verbs also indicates a result state. The present perfect is pragmatically odd with pure process predicates in reporting recent events, as illustrated in $(14 \mathrm{a}-\mathrm{c})$ below, compared with the change-of-state verbs in $(14 \mathrm{~d}-\mathrm{e})$.
a. John has walked.
b. John has talked on the phone.
c. John has played tennis.
d. The sentry has moved.
e. The price has increased (slightly).

$(14 \mathrm{a}-\mathrm{c})$ with activity predicates are quite odd, considered as possible conversational contributions, compared with $(14 \mathrm{~d}, \mathrm{e})$. With activity predicates the preferred form to report a recent event is the perfect progressive such as John has been talking on the phone. Simple existential readings with activity predicates (i.e. 'an event of this kind exists in the past') are improved with stress on the auxiliary: John HAS talked on the phone (but generally his phobia makes that impossible). It appears that the non-progressive present perfect with unmarked stress is more natural with a predicate entailing an endstate. Note that (14d) leans strongly towards the translocation sense, and implicates that the sentry has not returned to his previous position-(14d) implicates 'The sentry is not where he was before', which is a kind of comparative endstate. Inferred likely readings for the activity predicates also tend towards result states. For example, (14c) is not a natural way to communicate 'John has been playing tennis', but is natural with the main implicature 'John knows how to play tennis'. John's knowing how to play tennis may be considered a consequence of his having played, and thus a kind of result state.

I conclude that a predicate denoting a minimal 'become A-er' change of state is a Vendlerian achievement. If the interpretation is durative (as with modification by a for adverbial), the denoted event consists of a series of minimal change achievements, and constitutes a process. An in adverbial or take time construction with a whole event duration interpretation indicates an accomplishment.

The distinction between change-of-state achievements and accomplishments is discussed further in the next section.

\subsection{Change-of-state achievements and accomplishments}

The previous section reviewed verbs like widen and increase, which entail only a comparative endstate (' $\mathrm{x}$ is A-er'). In contrast, verbs like quieten, ${ }^{8}$ cool, and clear may denote events with

\footnotetext{
${ }^{8}$ The verb quiet, rather than quieten, may be more natural for speakers of American English.
} 
either a comparative or a standard endstate (' $\mathrm{x}$ is $\mathrm{A}$ '). A verb in this group modified by an in adverbial may denote events with both types of endstate, and thus the interpretation of in adverbials with verbs in this group on a telic interpretation is variable, as illustrated in (15)-(17).

a. The room quietened in a few minutes.

b. 'The room was becoming quieter throughout a period of a few minutes, and at the end of that period the room was quiet.' accomplishment

c. 'At the end of a few minutes the room became quieter.' achievement

a. The soup cooled in a few minutes.

b. 'The soup was becoming cooler throughout a period of a few minutes, and at the end of that period the soup was cool.' accomplishment

c. 'At the end of a few minutes the soup became cooler.' achievement

a. The sky cleared in half an hour.

b. 'The sky was becoming clearer throughout a period of half an hour, and at the end of that period the sky was clear.'

c. 'At the end of half an hour the sky became clearer.' accomplishment achievement

The paraphrases in (15)-(17) show two points of contrast between achievements and accomplishments: (i) the in adverbial expresses the event delay with an achievement, and the event duration with an accomplishment, and (ii) an achievement has a comparative endstate, while an accomplishment has a standard endstate.

Now consider a third type of reading for the verbs in (15)-(17) with in adverbials, as in (18).

a. The room quietened in a few minutes.

'At the end of a few minutes (during which the room was noisy) the room became quiet.'

b. The sky cleared in half an hour.

'At the end of half an hour (during which the sky was overcast) the sky became clear.'

Note that in (18) the proposed characteristics of achievements and accomplishments with in adverbials are differently aligned: (18a,b) have the event delay reading associated with achievements in (15)-(17), but the standard endstate reading associated with accomplishments in (15)(17), so the question arises as to whether the predicates in (18) are achievements or accomplishments. The choice will also reflect the relative diagnostic importance of characteristics (i) and (ii) above.

I propose that the examples in (18) are best analysed as accomplishments, and characteristic (ii) is more important. A change-of-state achievement may be considered as a single transition to an identifiable endstate. I have reviewed above the evidence that the comparative endstate, associated with achievements, is a sufficient telos to license telic modification. However, although the comparative endstate is sufficiently identified to count as a telos, it is not uniquely specified, and thus a whole series of transitions to comparative endstates may fall under the same predicate. This repeatability of the non-unique comparative endstate underlies the process interpretation of change-of-state verbs, as in The room quietened for a few minutes, 
interpreted as 'Throughout a period of a few minutes the room progressively became quieter and quieter'.

A change-of-state accomplishment, on the other hand, is assumed to contain a process of iterated 'become A-er' transitions, and yet it has a necessary endpoint beyond which the event cannot continue. I propose that this endpoint, providing the telos, is the unique transition 'become A'. Holding constant the contextual factors which determine the standard value for interpreting $x$ is $A$, there is a particular degree of the relevant property which constitutes the lower bound of the property region which is the standard value. The transition to this value ('become A') is unique and non-repeatable, and provides the telos to a change-of-state accomplishment.

If we assume, then, that an accomplishment is characterized by a unique endstate, the aktionsarten, endstates, and adverbial interpretations are correlated as shown below. The event delay/duration readings of in adverbials do not always distinguish between achievements and accomplishments. The central property of the accomplishment reading is the unique, nonrepeatable telos, identified here as the onset of the standard endstate.

\begin{tabular}{|l|l|l|l|}
\hline process & $\begin{array}{l}\text { non-unique } \\
\text { endstate } \\
\text { (x is A-er) }\end{array}$ & $\begin{array}{l}\text { iterated } \\
\text { achievements }\end{array}$ & $\begin{array}{l}\text { in + event delay (odd) } \\
\text { for + event duration }\end{array}$ \\
\hline achievement & $\begin{array}{l}\text { non-unique } \\
\text { endstate } \\
\text { (x is A-er) }\end{array}$ & $\begin{array}{l}\text { single transition } \\
\text { (x is A) }\end{array}$ & $\begin{array}{l}\text { in + event delay } \\
\text { for + result state duration }\end{array}$ \\
\hline accomplishment & $\begin{array}{l}\text { unique endstate } \\
\text { achievements }+ \\
\text { final unique } \\
\text { transition }\end{array}$ & $\begin{array}{l}\text { in + event duration } \\
\text { for + event delay }\end{array}$ \\
\hline
\end{tabular}

Returning to the central issue of this paper, we see in this section that the distinction between The soup cooled in ten minutes and The soup cooled for ten minutes is not adequately described as a distinction between telic and atelic senses. Rather, the targeted contrast is between an accomplishment sense and a process sense.

I have proposed that the accomplishment sense of a deadjectival verb is characterised by the transition to a unique endstate, which I identify as the state denoted by $x$ is $A$, termed the standard endstate in the previous section. The claim that the endstate of a deadjectival accomplishment is the state denoted by $x$ is $A$ is developed further in the next section.

\section{The telos of deadjectival accomplishments}

In this section I discuss further the first main issue identified in the introduction: the nature of the telos of the event denoted by a deadjectival verb on an accomplishment interpretation.

In the introduction I outlined two accounts of the nature of the telos with deadjectival verbs, as diagrammed in (19). As in (19a), the standard telos view is that the accomplishment denoted by a deadjectival verb terminates with the transition to the standard value, and the telos is the transition which qualifies as 'become A'. The maximal telos view illustrated in (19b) is that an accomplishment event constitutes the traversal of a property scale with an upper bound; here the telos is the transition 'become maximally A'. 
a. the standard telos view

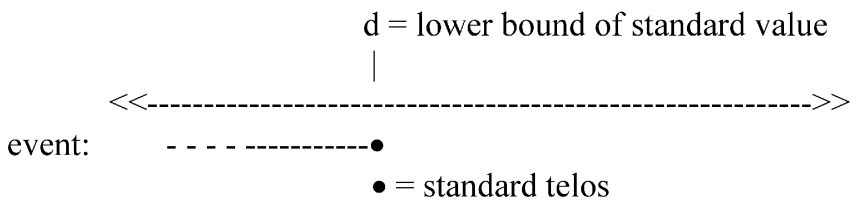

b. the maximal telos view

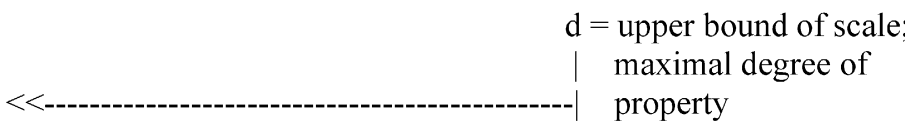

event:

- = maximal telos

These two views of the telos are compared in this section. Section 3.1 reviews Hay et al.'s theory in more detail. In sections 3.2 and 3.3 I identify preliminary problems with the data discussion in Hay et al.'s account, and clarify the data I will consider further. Sections 3.4 and 3.5 deal with deadjectival verbs associated with a closed property scale, and show that two kinds of telos are available with the accomplishment interpretation of these verbs, both of which are the onsets of the standard value. In section 3.6 I address Vanden Wyngaerd's (2001) analysis of bounding in resultative constructions, which appeals to closed property scales. I argue that resultatives, along with deadjectival verbs associated with closed property scales, denote events which are bounded by the onset of the standard value, not by the maximal value of the relevant property. Verbs associated with open property scales are discussed in section 3.7, where I show that the telos of an accomplishment interpretation is the onset of the standard value. The section is summarised in section 3.8 .

\subsection{The maximal telos view: Hay et al. (1999)}

Hay et al. frame their discussion in terms of the contrast between telic and atelic verb senses. With the proviso that the telic senses at issue are accomplishment senses, I shall use the term telic/atelic in presentation of their theory. I shall also use the descriptions verb derived from an open/closed-scale adjective and open-scale verb/closed-scale verb to refer to the verbs I have identified above as derived from a root which denotes an open/closed scale, and also surfaces as an adjective.

Hay et al. (p. 132) propose that deadjectival change-of-state verbs have the basic semantics in (20) below, ${ }^{9}$ where $\phi$ is the property which changes, $\operatorname{SPO}(e)$ is the start point of event $e, \operatorname{EPO}(e)$ is

\footnotetext{
${ }^{9}$ Intransitive verbs have the analysis in (20), and causative deadjectival verbs have the same schema with the causation component and external argument added. Hay et al. assume that the aspectual properties of both transitive and intransitive verbs arise from the nature of the difference value $d$ in (20), so the causative structure is omitted for ease of exposition.
} 
the end point of event $e$, and $d$ is the difference value - that is, the measure of change instantiated in the event. The analysis is illustrated in (21) (from Hay et al.'s (8a), p. 130 and (17a), p. 132).

$$
\begin{aligned}
& \text { [[ INCREASE }(\phi)(x)(d)(e)]]=1 \text { iff } \phi(x)(\operatorname{SPO}(e))+d=\phi(x)(\operatorname{EPO}(e)) \\
& \text { 'INCREASE }(\phi)(x)(d) \text { is true of an event } e \text { just in case the degree to which } x \text { is } \\
& \phi \text { at the beginning of the event plus } d \text { equals the degree to which } x \text { is } \phi \text { at the } \\
& \text { end of the event; i.e. just in case } x \text { increases in } \phi \text {-ness by } d \text { '' } \\
& \text { a. } \quad \text { Kim lengthened the rope. } \\
& \text { b. } \quad \exists e, d[\operatorname{INCREASE}(\text { long }(\text { rope } e)(d)(e)]
\end{aligned}
$$
a. Kim lengthened the rope.
'Kim caused the length of the rope to increase by some amount'
b. $\quad \exists e, d[\operatorname{INCREASE}($ long $($ rope $))(d)(e)]$

Hay et al. propose that deadjectival verbs have the semantics in (20) on both telic and atelic interpretations, and so are not formally polysemous. The difference between telic and atelic senses rests in the difference value $d$. If $d$ is bounded, then the interpretation is telic. If $d$ is unbounded, then the interpretation is atelic.

The most straightforward type of expression of a bounded difference value is found with measure phrases, as illustrated in (22) below (from Hay et al.'s (8b), p. 130 and (17b), p. 132). Here the difference value is identified as five inches, and is bounded. Accordingly, the sentence is telic.
a. Kim lengthened the rope by five inches.
b. 'Kim caused the length of the rope to increase by five inches.'
c. $\quad \exists e[\operatorname{INCREASE}($ long $($ rope $))($ five inches $)(e)]$

One of the goals of Hay et al.'s paper, drawing on work by Hay (1998), is to account for observed correlations between the availability of (a)telic readings for deadjectival verbs and the closed or open structure of the associated property scale. A closed scale has an upper bound, comprising the maximal degree of the property and denoted by completely $A$, beyond which higher values do not exist. An open scale has no upper bound, and in principle the property can increase indefinitely.

Hay et al. argue that acceptable modification by proportional adverbs such as half and completely is diagnostic of closed-scale adjectives, as in (23a), and closed-scale adjectives yield telic verbs. The telic reading of the verb has the aktionsart of an accomplishment, which is revealed by almost modification, as in (23b), which can have the reading 'The paint dried to some extent but not completely - it became almost dry'. In addition, the verb from a closed-scale adjective is telic on Kenny's (1963:172-175) test revealing non-cumulativity, characteristic of telic predicates, as in $(23 \mathrm{c})$.
a. The paint is half-dry/completely dry.
b. The paint almost dried.
c. The paint is drying $\nrightarrow$ the paint has dried.

Open-scale adjectives are not modifiable by proportional adverbs, as in (24a), and yield atelic verbs (24b). I note that although (24c) is not anomalous, the in adverbial is interpreted as denoting the delay before the event occurred, which is typical of achievements and states, rather than denoting the event duration, which would signal an accomplishment (see section 2.3). In 
(24d) only the counterfactual reading is possible; 'The gap didn't widen in fact but there was a high probability that it would'. The verb is cumulative, as in (24e).
a. \# The gap was half-wide/completely wide.
b. The gap widened for an hour.
c. The gap widened in an hour.
d. The gap almost widened.
e. The gap is widening $\rightarrow$ the gap has widened.

Hay et al. propose that in the absence of overt aspectual modification, a sentence with a deadjectival verb gives rise to a quantity implicature that the reported event was 'complete'. If the verb is derived from a closed-scale adjective, a complete event is construed as one in which the theme argument attains the upper bound of the scale, and bears the maximal value of the property. This point is a natural telos, and accordingly the interpretation is telic. For example, the property scale DRY is closed, upper-bounded by a state of the complete absence of moisture. An unmodified sentence such as The clothes dried carries the quantity implicature 'completely', giving the interpretation 'The clothes dried completely/became completely/maximally dry'. Given this implicature, Kenny's entailment does not go through: The clothes are drying does not entail The clothes have dried on the enriched interpretation 'The clothes have dried (completely)'. The scale for WIDE, on the other hand, is open, there being no maximal possible degree of wideness in principle. The 'completely' implicature has no particular interpretation with this scale, and so does not attach to sentences with verb widen. Widen is always atelic, ${ }^{10}$ and Kenny's entailment goes through: The gap is widening entails The gap has widened.

So far, we see that in Hay et al.'s theory the default aspectual interpretation of a deadjectival verb stems from its property scale. A closed-scale verb has a default telic (accomplishment) interpretation, and an open-scale verb has a default atelic (process) interpretation. In order to account for telicity alternations, Hay et al. outline several ways in which the default readings may be altered.

First, as we have seen, a measure phrase such as (by) five inches provides an explicitly bounded difference value, and therefore no quantity implicature of completeness arises, regardless of the nature of the property scale.

Second, Hay et al. argue that the 'completely' implicature can be cancelled by modification with a for adverbial (p. 138) or by explicit denial with but not completely (p. 137).

Third, a verb derived from an open-scale adjective may have a telic interpretation, Hay et al. propose, in particular collocations and contexts. For example, although lengthen and lower are normally open-scale verbs (cf. \#completely long, \#completely low) and atelic, in the collocations illustrated below they may be associated with closed scales, and telic.

a. The tailor lengthened my pants.

b. Kim lowered the blind.

Hay et al. observe (p. 136) that '[r]eal-world knowledge informs us that there is a conventional maximal length for pants, and a conventional degree beyond which there is no need for blinds to

\footnotetext{
${ }^{10}$ Here, to say that widen is atelic is to claim that it lacks an accomplishment sense. The achievement sense discussed in section 2 is not relevant here.
} 
be further lowered', or 'at which they cannot be further lowered' (p. 137). Thus in these contexts the events may be interpreted as 'maximal' and the verbs as telic, and Kenny's entailment does not go through: The tailor is lengthening my pants does not entail The tailor has lengthened my pants.

A contextually supplied telos is also invoked for the telic variant in The soup cooled in/for ten minutes, where the collocated argument is held constant. Here, Hay et al. observe (p. 138): 'The sentence The soup cooled is most informative on a telic interpretation: the soup cooled to some bounded degree. Such a reading is possible in this example because such a degree is salient, namely room temperature'.

The predictions of the theory reviewed here are summarized in the diagram below, with example sentences for each type.

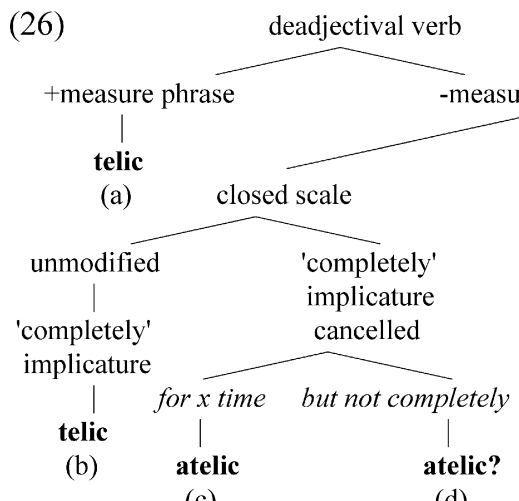

(c)

(d)

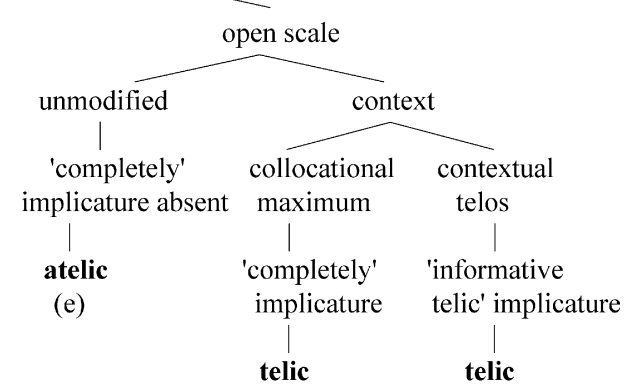

(f)

(g)

(a) Kim lengthened the rope five inches.

(b) The clothes dried.

(c) The clothes dried for an hour.

(d) The clothes dried, but not completely.

(e) Kim lengthened the rope.

(f) Kim lowered the blind.

(g) The soup cooled.

I shall identify problems with this account, and propose alternatives. First, in sections 3.2 and 3.3 I discuss issues with the data Hay et al. cite, before proceeding to a reconsideration of the nature of the telos.

\subsection{The significance of completely modification}

Recall that Hay et al. argue that acceptable modification by completely is diagnostic of a closed-scale adjective (completely dry, cf. \#completely long), where completely A denotes the maximal value on a bounded property scale. They also argue that the most informative interpretation (including a quantity implicature) of a closed-scale verb is one in which the event is 'complete': 'The most informative interpretation of They straightened the rope then is one in 
which the rope is straightened completely' (p. 137), and this is the telic interpretation. Accordingly, They straightened the rope (on a telic interpretation) is interpreted by implicature as having the sense explicitly given in They straightened the rope completely, where the adverb expresses 'all the way to the upper bound of the scale'.

Kennedy and McNally (1999:178 fn. 1) point out that modifiers like completely and totally have 'both an endpoint-oriented use and a use that is roughly synonymous with very'. ${ }^{11}$ The endpoint-oriented use, entailing that the end of a scale is reached, is shown by the contradictoriness of examples like The line is completely/totally straight, though you can make it straighter, where modified straight is associated with a closed scale. The intensifier use is shown by the lack of contradiction with I'm completely/totally uninterested in finances, and Bob is even less interested than me, where uninterested does not have a maximal value. I concur with Kennedy and McNally's general point, that completely modifying an open-scale expression is not oriented to the upper bound of a property scale. However, I consider that this use is still oriented to a boundary - it is oriented to the lower bound of the standard region of the property at issue, relativised to context. I consider that this use is not synonymous with very, but is closer in force to unquestionably, definitely or indubitably. Thus He is completely uninterested in finances conveys 'He is definitely/indubitably uninterested in finances'. However, the point remains that completely is not always oriented to a maximal property value, and so the mere acceptability of completely modification is not sufficient to show that an adjective is associated with a closed scale. The presence of a closed scale is shown by an entailment of the form in (27). Where an entailment of this form holds, completely $A$ does denote a maximal value.

' $\mathrm{x}$ is completely A' entails ' $\mathrm{x}$ could not be A-er.'

As we see in (28)-(31), the verbs cool, darken, dry and quieten and their base adjectives all take completely modification.
a. The soup cooled completely.
b. The soup is completely cool.
a. The sky darkened completely.
b. The sky is completely dark.
a. The clothes dried completely.
b. The clothes are completely dry.
a. The room quietened completely.
b. The room is completely quiet.

However, the examples in (32), where '!' indicates contradiction, show that completely cool does not denote a maximal value, and presumably cool does not have a closed scale. In (32a) completely cool is interpreted as 'definitely/unquestionably cool'; in other words, it is incon-

\footnotetext{
${ }^{11}$ Paradis (2001) cites the use of completely, totally, absolutely and so on as intensifiers with extreme value adjectives such as brilliant and marvellous, which resist very: cf. absolutely brilliant, \#very brilliant. Although it seems that extreme adjectives require totality modifiers as intensifiers, intensifier completely, totally and so on are not restricted to extreme adjectives-He's completely ordinary and It's totally $O K$ are normal colloquial usage.
} 
testable that the standard value for coolness, given the context, has been reached. Dry, quiet and dark, however, do have closed scales; completely modification is upper-bound oriented, and the assertion of the existence of higher values produces a contradiction.
a. The soup is completely cool now, but it could be cooler.
b. ! The clothes are completely dry now, but they could be drier.
c. ! The room is completely quiet now, but it could be quieter.
d. ! The sky is completely dark now, but it could be darker.

From now on, I shall assume that completely $A$ denotes a maximal value, and thus indicates an upper bounded scale, only if the entailment ' $x$ could not be A-er' holds for the adjective concerned. In collocation with an open-scale expression, completely has the intensifier sense 'indubitably, unquestionably', and is oriented to the lower bound of the standard value.

\subsection{Lengthen pants, lower blind, and action scripts}

Recall that Hay et al. argue that the examples repeated in (33) below are telic because the collocations provide maximal values for scales which would otherwise be open.

a. The tailor lengthened my pants.

b. Kim lowered the blind.

It is argued that lengthen is associated with a closed scale for long in collocation with pants because by convention pants have a maximal length beyond which they may not be lengthened. Similarly, a blind can be lowered so far and no further according to its mechanism, so lower in collocation with blind is associated with a closed scale for low.

I point out here that although the telicity of lower blind and lengthen pants reflects a bounded event; it does not reflect an underlying bounded property scale of lowness or length. Deadjectival verbs, particularly transitive verbs, may have event structures based on action scripts - that is, prototypical courses of actions performed by the agent - rather than on a gradual property change in the theme. ${ }^{12}$ Lengthen pants is associated with a script which is very like that for shorten pants or alter pants, the main components being to unpick the old stitching, re-pin the garment to the new configuration, and re-stitch it. ${ }^{13}$ The event structure of lengthen pants is given by this sequence of actions. The predicate does not denote a caused gradual increase in the length of the pants, and at the half-way point in the event the pants are not at a length halfway between the initial and final length. In fact, the event structure of the predicate is not associated with a property scale at all, and consequently the telicity of these examples does not provide evidence for contextually licensed closed scales for adjectives such as low and long, which generally are associated with open scales.

Note that if a contextual maximal value for the scales of long and low were provided by collocation with pants and blind respectively, then the same collocation should also license

\footnotetext{
${ }^{12}$ The same point is made in Rothstein (2004:119).

${ }^{13}$ Hay et al.'s comment (p. 137) that the most informative interpretation of The tailor lengthened my pants 'is the one in which the tailor finished his job' tends towards a script-based view of the event aspect, but elsewhere (pp. 136, 137) the telicity of the example is ascribed to 'a conventional maximal length for pants'.
} 
other indicators of the presence of closed scales for long and low, including endpoint-oriented completely modification. But as the examples in (34) show, the collocations do not license endpoint-oriented completely, and the entailments we should see with closed scales actually fail.
a. $\quad$ The tailor finished lengthening my pants $\rightarrow$ \# my pants are completely long.
b. $\quad$ Kim lowered the blind completely $\rightarrow$ \# the blind was completely low.
cf. The blind was completely lowered/right down.

The same difficulty, that the structure of an event is mapped from an action script, rather than from a gradual property change, also occurs with numerous other transitive deadjectival verb predicates, such as widen the road and possibly lengthen the rope; the rope may be gradually lengthened by weaving or it may be lengthened all at once by tying a new piece to it. Examples like these can tell us nothing about the relationship between the property scale canonically associated with a deadjectival verb and the aspect of an event, as the property scale plays no part in the aspectual interpretation of these examples.

The deadjectival verb interpretations at issue in this paper are those for which the event structure is mapped from gradual property change, represented as the theme's traversal of a property scale associated with the verb and its corresponding adjective. Deadjectival verb collocations which are interpreted according to scripts of the agent's actions are uninformative, and will be excluded.

Script-based aspect is a potential problem for any transitive uses of deadjectival verbs, as the unspecified actions of the agent are available in principle to provide part of the event structure, and thus we cannot be sure that the change of state of the theme provides the event structure. For example, John started heating the soup may be true of an event in which John has placed the soup in a pot and exposed it to heat, but the soup has not yet undergone a change in temperature. To exclude the possible interference of an agent's actions on how an event is structured, I shall use only intransitive verbs in the following discussion. ${ }^{14}$

Among intransitive verbs, I shall also exclude examples like The sauce thickened, which denotes an event that is not simply the traversal of the property scale of thickness, but also requires a characteristic chemical change to a particular state, which provides a telos. The attainment of this state is appropriately described with The sauce is completely thickened, but cannot be described by \#The sauce is completely thick. I conclude that thicken in collocation with sauce does not simply denote the traversal of the thickness property scale, and although the sauce does in fact become thicker, the event structure is really based on the chemical change, and sauce thicken has a kind of script aspect.

I shall also exclude examples such as The days lengthened, which does not denote a change of state in which a theme traverses a property scale. It is not the case that any day or days actually increase in length; rather, each day in a series is longer than the previous day. This is not a changeof-state predication. Similarly, there is no change-of-state predication in Towards the river the path narrowed. The path near the river is narrower than the path further away from the river, but no path or part of the path undergoes a change of state.

\footnotetext{
${ }^{14}$ Leaving aside transitive verbs restricts the available data considerably, as many deadjectival verbs have intransitive uses in quite limited collocations (see Levin and Rappaport Hovav (1995), Chapter 3 for discussion of factors in the causative alternation).
} 
Finally, in order to focus on the theme's change of state as the source of event structure, it is also necessary to distinguish between holistic and incremental themes (see Dowty, 1991). The theme is interpreted as holistic where the event structure is mapped from the traversal of a property scale; the successive degrees of a property are borne by the whole theme as the event unfolds. For example, on the holistic theme interpretation of The clothes dried, all the clothes together progressively became drier and drier through the course of the event. The holistic theme interpretation is the intended interpretation in the following discussion.

The incremental theme interpretation of change-of-state, on the other hand, does not have an event structure mapped from the traversal of a property scale. Rather, the parts of the event are mapped from parts of the theme which successively undergo the change of state. For example, on an incremental theme interpretation The clothes dried denotes an event in which different parts of the clothes became dry at different times throughout the event. The incremental theme interpretation, where it is available, is not the intended interpretation in the following discussion.

To sum up, I focus on the aspectual properties of deadjectival verbs which denote an event mapped from the change of state undergone by the theme argument. To exclude uses of deadjectival verbs with other event structures, I exclude transitive verbs, incremental theme interpretations, and collocations such as sauce thicken which have special script-like event structures.

\subsection{The nature of the telos for verbs associated with closed-scale adjectives}

Recall that the central claim in Hay et al.'s theory is that the structure of the property scale associated with an adjective provides a default telic or atelic sense for the corresponding verb (in the absence of aspectual modification). The upper bound of a closed scale provides a telos for the interpretation of implicated 'completely', and accordingly the telos of the telic sense of such a verb is the onset of the maximal endstate. I shall argue against this view here, and show that the telic (accomplishment) sense of a deadjectival verb uniformly entails the standard endstate - that is, the state denoted by $x$ is $A$.

Adjectives such as dark, ripe and quiet are associated with closed scales, and a true maximal value is denoted by completely $A .{ }^{15}$ Interpreting completely $A$ as denoting a maximal value is consistent with intuitions about the examples in (35) below. In (35a) there is no sound at all in the room, and so lower sound levels are impossible; in (35b) there is no light in the sky and lower light levels are impossible; and in (35c) any further maturing of the fruit will constitute decay rather than further ripening.
a. The room is completely quiet.
b. The sky is completely dark.
c. The fruit is completely ripe.

However, a telic reading of the corresponding verb does not entail the maximal endstate denoted by $x$ is completely $A$, but merely the standard endstate, denoted by $x$ is $A$. This is illustrated in

\footnotetext{
${ }^{15}$ Recall from section 3.2 that the non-upper-bound-oriented use of completely appears with open-scale expressions, but not with closed-scale expressions such as the adjectives in (35). Where a true upper bound is available completely will be interpreted as modifying it.
} 
(36)-(38). In the (a) examples we see that the accomplishment interpretation of the verb (taking the in adverbial to state the event duration) is compatible with the denial of $x$ is completely $A$. This shows that the accomplishment sense of the verb does not entail $x$ is completely $A$, and thus $x$ is completely $A$ cannot be the required telos for the accomplishment. In the (b) examples, however, the accomplishment sense of the verb is shown to be incompatible with denial of the standard endstate. The contradictory (b) examples show that the accomplishment senses of these verbs do entail the standard endstates denoted by $x$ is $A$.

a. The room quietened in a few minutes but it wasn't completely quiet.

b. ! The room quietened in a few minutes but it wasn't quiet.

a. The sky darkened in an hour but it wasn't completely dark.

b. ! The sky darkened in an hour but it wasn't dark.

a. $\quad$ The fruit ripened in five days but it wasn't completely ripe.

b. ! The fruit ripened in five days but it wasn't ripe.

Note also that Hay et al. account for some telicity alternations by appealing to the cancellation of implicature (see section 3.1). On their account the telic interpretation of a deadjectival verb arises from an implicature of completeness, but this implicature can be cancelled by a for adverbial, giving an atelic interpretation. Thus The sky darkened for a few minutes can have a process interpretation, because the 'darkened completely' implicature is cancelled by the adverbial. Hay et al. also note the acceptability of but not completely with a sentence which is otherwise telic by implicature. For example, they observe that The tailor lengthened my pants, but not completely (their (32a), p. 137) is acceptable because 'the implicature that the change is bounded can be cancelled'.

Given their identification of telicity as the attainment of the maximal endstate with closedscale verbs, Hay et al. do not address an important difference in the two claimed types of implicature cancellation. When a for adverbial is added, and by Hay et al.'s account cancels the implicature of completeness and therefore telicity, the resulting sentence is indeed atelic, as in The sky darkened for an hour. However, when a conjoined but not completely explicitly cancels the implicature of completeness, the sentence may nevertheless remain telic, as in (39) (where the in adverbial has the event duration reading signalling an accomplishment).

a. The sky darkened in an hour, but not completely.

b. ! The sky darkened in an hour but it wasn't dark.

In (39a) the telos is the state of the sky being dark, which is not the same as the state of the sky being completely dark, and hence the continuation in (39a) is not contradictory. In contrast, the contradiction in (39b), repeated from (37b), shows that the telos of the accomplishment event is indeed the state of the sky's being dark.

I conclude that the endstate of these verbs on an accomplishment interpretation is not the maximal endstate, but the standard endstate.

\subsection{Closed-scale adjectives which lexicalize maximal values}

I turn now to deadjectival verbs with telic senses which may entail a maximal endstate, consistent with Hay et al.'s account, such as clear and dry. With these adjectives and their 
corresponding verbs, proportional modification generally expresses proportions of an inprinciple maximum value, and the telic verb entails the maximal endstate.
a. The paint dried in an hour $\rightarrow$ the paint was completely dry. ${ }^{16}$
b. The paint was completely dry $\rightarrow$ the paint could not have been drier.

Adjectives in this group differ from those like cool and dark, in that the (unmodified) positive adjective in this group on a strict interpretation does express the maximum value of the relevant property. Concerning adjectives in this group, Rusiecki (1985) notes the entailments in (41a-c) below, which show that where two entities are unequal in the relevant property, $x$ is $A$ cannot be true of the lower-ranked entity. It follows from this that the positive form $A$ with these adjectives lexicalises the maximal degree of the property. The examples in (41d-f), included for comparison, show that the corresponding entailment is not found with quiet, dark, and ripe, even though quiet, dark and ripe are also associated with closed property scales. As we saw in section 3.4, adjectives in the quiet group do not lexicalise the upper bound of the associated property scale, and with these verbs the standard value and the maximal value are different.
a. $\quad$ This towel is drier than that towel $\rightarrow$ that towel is not dry.
b. This bag is emptier than that bag $\rightarrow$ that bag is not empty.
c. The sky is clearer than it was an hour ago $\rightarrow$ the sky was not clear an hour ago.
d. This room is quieter than the library $\nrightarrow$ the library is not quiet.
e. The sky is darker than it was an hour ago $\nrightarrow$ the sky was not dark an hour ago.
f. This apple is riper than that apple $\nrightarrow$ that apple is not ripe.

We see that the positive adjectives in the dry/clear group lexicalise the maximal value of the relevant property. Now given that the standard value is identified as the degree of a property expressed in $x$ is $A$, we can conclude that the standard value with these adjectives is the maximal value. The endstate entailed by the accomplishment interpretation of the corresponding verbs is at once both the standard endstate and also the maximal endstate. Accordingly, these verbs also fall under the generalisation that the endstate of a deadjectival verb on the accomplishment interpretation is the standard endstate. In short, the accomplishment verb entails ' $x$ is $A$ '. With verbs of the dry type, but not the dark type, ' $\mathrm{x}$ is A' also entails ' $\mathrm{x}$ is maximally $\mathrm{A}$ '.

\subsection{The bounding of resultatives}

In this section I shall propose that the resultative construction, in which the resultative adjective phrase expresses the endstate of the theme, provides further support for my claim that a standard endstate may bound an event.

Vanden Wyngaerd (2001) argues that a resultative construction is bounded by the resultative phrase, and that only a closed-scale adjective can bound a resultative construction. To account for

\footnotetext{
${ }^{16}$ The claimed entailment in (40a) may not appear with all collocations for dry. The clothes dried in an hour, but they weren't completely dry is acceptable. I suggest that the difference here stems from the different collocations, producing possible different criteria for calling something dry. Clothes that are dry enough to be brought in and ironed may be slightly damp, but may count as 'dry' according to the purpose for which the judgment is made. Thus, the clothes may be 'dry' in the sense of 'dry enough for the present purpose' but not 'completely dry'. Paint, on the other hand, is not said to be dry until all detectable moisture has evaporated, and in this context dry entails 'maximally dry'.
} 
the fairly free occurrence of apparently open-scale adjectives in resultatives, Vanden Wyngaerd proposes that otherwise open-scale adjectives shift to a closed-scale interpretation in the resultative.

In Hay et al.'s account, closed-scale verbs have a default telic interpretation in which the upper bound of the associated property scale provides the telos (via a quantity implicature). Without this assumption, the association of telicity with closed scales would be mysterious - if the telos were not mapped from the upper bound of the property scale, why should the presence of an upper bound provide a telic verb sense?

Vanden Wyngaerd's argument is not quite the same. He argues that proportional modification with almost, half and entirely is diagnostic of closed-scale adjectives, and that the free appearance of proportional modifiers in resultative phrases, as illustrated in (42), is evidence that an adjective in a resultative phrase has a closed-scale sense, even if it seems to be an open-scale adjective in other contexts. He does not explicitly claim that the (unmodified) resultative phrase denotes a maximal value.

Max shouted himself completely hoarse.

Max shouted himself half-hoarse.

Max shouted himself almost hoarse.

I shall offer an alternative view of the significance of these modifiers. First, I emphasise that nothing is explained by claiming that only a closed-scale adjective can provide a telos, unless the telos is provided by the upper bound of the scale. Second, recall that completely with open-scale expressions has a non-endpoint-oriented use, as reviewed in section 3.2 above. If the modifiers in (42) are to be evidence that the adjectives denote closed scales, then it must be shown that the modifiers have a proportional interpretation with reference to an upper bound. If the adjective in a resultative expresses a closed scale, and the modifier is interpreted proportionally on the scale, then presumably the state denoted by half $A$ is 'A to an extent halfway to the maximum' (cf. John packed the sack half-full) and almost $A$ denotes the state 'pretty A, but not as A as possible/not completely A' (cf. John packed the sack almost full). Only readings of this kind would constitute evidence that a scale bounded by a maximal value is involved.

Vanden Wyngaerd's examples are generally not interpreted with reference to a maximal value. The examples in (43) are taken from his examples (10-11), (p. 64).
a. Otto laughed himself almost/half sick.
b. Jeroen talked himself almost/half drowsy.
c. Marijke ate herself almost/half fat.
d. Max shouted himself almost/half hoarse.
e. Charley laughed himself almost/half silly.

In all these examples, almost and half produce a counterfactual reading with respect to the property denoted by the adjective. That is, at the end of the event Otto was not sick (43a), Jeroen was not drowsy (43b), and so on. Depending on the example, some change of state short of the property denoted by the adjective may be understood to hold. For example, in (43a) Otto may be gasping for breath, in (43b) Jeroen may be flagging a little but not drowsy, in (43c) Marijke may be rather plump but not fat, and so on. In short, the effect of almost and half in (43) is to define the result state of the event as falling short of the threshold of the state denoted by $x$ is $A$, not falling short of a maximal value. 
Vanden Wyngaerd presents the same examples with entirely (e.g. Marijke ate herself entirely fat), which to my judgement is awkward, but presumably should have the same effect as modification with completely, which is less awkward. Even so, the result phrase need not entail a maximal state, as shown by Over the winter Marijke ate herself completely fat, but nowhere near as fat as she used to be.

Vanden Wyngaerd's argument, that the need for a closed-scale adjective in a result phrase is demonstrated by the acceptability of proportional modification, is called into question by his examples shown in (44). Here, the unmodified resultative in (44a) is acceptable but the modifications in (44b) are quite anomalous, which suggests that thin in (44a) has the usual open-scale interpretation which is apparently also indicated by the anomalous modifiers in $(44 b, c)$.

(44) a. The joggers ran the pavement thin.

b. \# The joggers ran the pavement entirely/almost/half thin.

c. \# The pavements were entirely/almost/half thin.

In any case, whether or not the adjective in a result phrase has a closed scale, an unmodified result phrase simply expresses the state which is usually expressed by the head adjective. That is, Marijke ate herself fat in three months does not entail that at the end of the event Marijke was maximally fat, but simply that she was fat, and the same applies to Max shouted himself hoarse, and so on. Concluding that the endstate of an unmodified resultative is the state denoted by $x$ is $A$, where $A$ is the head of the result phrase, we see that the resultative construction provides additional evidence that a standard endstate is an adequate accomplishment telos.

\subsection{Verbs derived from open-scale adjectives}

For verbs which alternate between process and accomplishment senses in collocation with the same argument, as in The soup cooled in/for ten minutes, Hay et al. propose that the context provides a normative telos for the event, in this case when the soup reaches room temperature. The resulting explicature 'The soup cooled to room temperature' can license an in adverbial. But if a for adverbial is present, the implicature 'to room temperature' is cancelled and the reading is atelic.

a. The soup cooled ('to room temperature' by implicature) in ten minutes.

b. The soup cooled ('to room temperature' implicature cancelled) for ten minutes.

The implicature that Hay et al. claim for telic The soup cooled is not the same as the informativeness implicature of 'completely' that they propose for The clothes dried. Rather, Hay et al. suggest that 'The soup cooled is most informative on a telic interpretation: 'the soup cooled to some bounded degree'. However, the suggested room temperature does reflect an underlying assumption of a kind of possible maximum - the soup cannot normally cool beyond room temperature without intervention, such as refrigeration. Note that if we take the informativeness implicature at work, that the soup cooled 'to some bounded degree', not to appeal to some understood maximum, then it is difficult to see what is added by the implicature. As I showed in section 2, every change of state denoted by The soup cooled does in fact result in some (indefinite) bounded degree of change. 
I agree that the telos for The soup cooled is given by context and convention, and the context provides a normative telos for the event. However, I argue that this is because (i) the telos is provided by the standard endstate, denoted by $x$ is $A$, and (ii) the standard value is a normative value, given by context and convention.

The contextually determined telos for a soup cool event correlates with contextual criteria for applying the positive adjective cool.

(46) a. The soup cooled in ten minutes so we had to reheat it.

b. The soup is cool now so I'll have to reheat it.

c. The soup cooled in ten minutes so we started eating it (before it cooled too much)

d. The soup is cool now so please start eating before it gets too cool.

In $(46 \mathrm{a}, \mathrm{b})$, the context provides the salient presupposition that soup should be eaten hot, and here cool is interpreted as 'too cool to eat'. A different context, as in $(46 \mathrm{c}, \mathrm{d})$, provides the salient presupposition that soup can be too hot to eat, and cool is interpreted as 'cool enough to eat'. In both of these scenarios the telos of the event is the onset of the state denoted by The soup is cool. This is also shown by the contradictoriness of The soup cooled in ten minutes but it wasn't cool (where the in adverbial expresses the event duration).

Note also that completely modification in these examples has the interpretation claimed for completely with open-scale expressions in section 3.2, where the sense 'indubitably, unquestionably' is oriented to the lower bound of the state denoted by $x$ is $A$. This is illustrated in (47).

(47) a. The soup cooled completely in ten minutes so we had to reheat it.

'The soup became unquestionably cool.'

The contextual standard for $\mathrm{cool}=$ 'too cool to eat'

b. The soup is completely cool now so I'll have to reheat it.

'The soup is unquestionably cool.'

The contextual standard for $\mathrm{cool}=$ 'too cool to eat'

c. The soup cooled completely in ten minutes so we started eating it before it cooled too much.

'The soup became unquestionably cool.'

The contextual standard for $\mathrm{cool}=$ 'cool enough to eat'

d. The soup is completely cool now so please start eating before it gets too cool.

'The soup is unquestionably cool.'

The contextual standard for $\mathrm{cool}=$ 'cool enough to eat'

\subsection{Summary}

I conclude, then, that (48) holds.

(48) The telos of a deadjectival verb on the accomplishment reading is the onset of the standard endstate. The standard endstate is the state denoted by $x$ is $A$ (where $A$ is the positive form of the corresponding adjective) holding constant the contextual and collocational factors for interpreting the positive adjective. 
This allows a simple, unified account of the following cases.

(i) Verbs like darken and quieten are associated with closed property scales, but in their accomplishment senses do not entail the maximal endstate, but only the standard endstate.

(ii) Verbs like dry and empty are also associated with closed property scales. However, unlike darken and quieten, the positive adjective for verbs in this group lexicalises the maximal property value, and $x$ is $A$ entails ' $\mathrm{x}$ is maximally A'. The accomplishment sense of dry/empty verbs entails the maximal endstate, but this still falls under the generalisation that the entailed endstate is the standard endstate.

(iii) Verbs like cool are associated with open property scales, but have accomplishment senses which entail the standard endstate. There is no need to propose contextually given natural endpoints which are implicitly identified as contextual upper bounds to the property scale. That is, there is no need to propose that an otherwise open property scale is closed just in case the verb is telic.

I have also shown that the assumption that the standard endstate supplies an accomplishment telos extends straightforwardly to resultatives, in which a positive adjective directly expresses the telos.

\section{Predicting process and accomplishment senses of deadjectival verbs}

Here I address the second main issue identified in the introduction, the problem of predicting the availability of accomplishment and process senses. Section 4.1 reviews the predictions of Hay et al.'s account, and shows that the account does not really distinguish verbs that alternate in telicity from those that do not. I then offer an alternative view, relating the prediction of verb senses to the interpretation of the standard value for the relevant property. Section 4.2 discusses verbs with default accomplishment readings, and section 4.3 deals with verbs that resist accomplishment readings. In section 4.4 I propose that Hay et al.'s analysis of deadjectival verbs can be easily modified to take the present findings into account, by altering the content of the quantity implicature which gives rise to accomplishment senses.

In section 4.5 I shall turn to a further issue arising out of assumptions which I share with Hay et al. I agree with Hay et al.'s view that the comparative endstate sense 'become A-er' is the basic sense of all deadjectival verbs, and accomplishment senses arise by implicature. However, the claim that the 'become A-er' sense is basic seems inconsistent with the evidence that some deadjectival verbs resist process senses-we would expect that the sense claimed as basic would appear in at least some contexts for all deadjectival verbs. I show that even those verbs with strong default accomplishment senses can take a process sense.

\subsection{Predicting process and accomplishment senses in Hay et al.'s account}

As outlined in section 3.1, Hay et al. propose that all deadjectival verbs have a basic process reading, defined in terms of INCREASE. An unmodified closed-scale verb carries a quantity implicature 'completely', giving a telic (accomplishment) sense in which the upper bound of the property scale provides the telos. An unmodified open-scale adjective, having no upper bound, cannot provide a telos for the 'completely' implicature to attach to, and has an atelic (process) reading. 
To account for the telicity alternations found with many verbs, Hay et al. propose two types of mechanism. First, an otherwise open-scale verb may have a telic sense where context and/or collocation provide a telos for the event. Second, a closed-scale verb may have an atelic sense where the 'completely' implicature is cancelled by modification with a for adverbial or by but not completely.

Consider first the issue of a contextually provided telos for an open-scale verb. Hay et al.'s theory does not predict why context can supply an upper bound for cool and an accomplishment sense for The soup cooled, but apparently cannot supply an upper bound for verbs like widen: The gap widened in ten minutes has only the achievement sense 'Within ten minutes the gap became wider' (see example (12), section 2.1, and footnote 7). In addition, wide and cool differ in the availability of endpoint-oriented modification, as illustrated in (49)-(50). We need an account of why widen differs from cool in this way.
a. \# The gap was half-wide/completely wide.
b. \# The gap widened (completely) in 90 seconds.
a. The soup was half-cool/completely cool.
b. The soup cooled (completely) in ten minutes.

Concerning the cancellation of the 'completely' implicature, I have already pointed out (section 3.4) the apparent inconsistency of the two types of implicature cancellation. Recall that a closedscale verb as in The clothes dried carries an implicature 'completely', giving an interpretation in which the theme of the event attains the upper bound of the scale (i.e. complete dryness). Thus the sentence is interpreted as 'The clothes dried completely/The clothes became completely dry'. Given that the 'completely' implicature in combination with a closed-scale verb is the source of the telic sense, cancellation of the implicature should result in an atelic sense. But this is not the case: The clothes dried in an hour, but not completely is acceptable on an accomplishment reading. On the other hand, acceptable modification with a for adverbial on the event duration reading is indeed diagnostic of a process, so the two proposed types of implicature cancellation have different outcomes.

In addition, Hay et al.'s theory does not predict the relative availability of cancellation of the accomplishment implicature with a for adverbial. Closed-scale verbs vary in this regard, as illustrated in (51). The judgments marked here are not intended to reflect absolute values of wellformedness; they are intended to indicate the relative acceptability of the examples on the process reading, with the for adverbial giving the duration of the event. Note that the examples are much improved with the for adverbial interpreted to modify the result state, which is irrelevant here. Progressive forms of the examples are included for comparison, to clarify the intended process reading.

(51) a. The sky darkened for an hour. cf. The sky was darkening for an hour.

b. (?) The clothes dried for an hour. cf. The clothes were drying for an hour.

c. (?) The sky cleared for an hour. cf. The sky was clearing for an hour.

d. ? The tank filled for an hour (while the pump was working). cf. The tank was filling for an hour. 
e. (\#) The tank emptied for an hour (while the pump was working). cf. The tank was emptying for an hour.

f. \# The door closed/shut for a few seconds (then John stopped it with his foot.) ${ }^{17}$ cf. The door was closing/shutting for a few seconds.

To sum up: The correlation Hay et al. propose between open and closed scales and process or accomplishment verb senses has to be modified to take into account the large number of alternating verbs. Hay et al. propose two kinds of adjustment, one for accomplishment senses of open-scale verbs, and one for process senses of closed-scale verbs. Neither modification includes a basis for predicting when it may operate, and so we don't know why open-scale verbs such as widen resist accomplishment senses, nor why closed-scale verbs such as empty and close resist process senses. Both these issues will be taken up below.

\subsection{Maximal state adjectives and default accomplishment senses}

Closed-scale verbs were ranked in (51) above according to the relative ease with which they take process senses. Given that all these verbs map to a closed scale, scalar structure alone cannot predict the variation illustrated in (51). However, the ranking indicated in (51) can be shown to correlate with differences among the senses of the associated positive adjectives.

Although dark is associated with a closed scale, adjective dark does not express a maximal value, and the verb dark takes a process sense fairly freely. Similar verbs are quieten and ripen.
a. The sky darkened for an hour.
b. The room quietened for a few minutes (as the children became absorbed in the game).
c. The fruit ripened for another week.

Dry and clear express maximal values on a strict interpretation, though context and collocation may affect the strictness of interpretation. Clothes may be called dry while still dampish, if they are judged to be 'dry' for the purpose of bringing them in to be ironed. Paint, on the other hand, is not called $d r y$ while it is still tacky. Skies may be called clear when a few small clouds are present, so sky clear is like clothes dry. These adjectives may be described as flexibly maximal, and their verbs take a process reading a little less readily than verbs in the dark group. As for (51) above, the judgments indicated in (53)-(54) are intended to indicate only relative naturalnessthe (b) examples are marginally more awkward than the others.

(53) a. The clothes dried for an hour.

b. (?) The paint dried for an hour.

c. The sky cleared for an hour.

(54) a. The clothes are dry, but not completely dry.

b. (?) The paint is dry, but not completely dry.

c. The sky was clear, but not completely clear.

\footnotetext{
${ }^{17}$ I have included close here as a verb related to an adjective (closed) with a closed scale, although presumably close is not a deadjectival verb-the adjective here is participial. I assume the direction of derivation does not affect the point made.
} 
Fill and empty, though apparently expressing maximal values of the same kind, vary in strictness of interpretation. Full expresses a maximal value more loosely than empty, cf. (55a) and (56a). Correlating with this contrast, the verb fill takes a process sense more readily than empty, cf. (55b) and (56b). Note that this variation is not produced by different arguments in collocation, cf. paint dry and clothes dry.

(55) a. The tank is full, but it was fuller last night.

b. ? The tank filled for an hour.

a. (\#) The tank is empty, but it was emptier last night.

b. (\#) The tank emptied for an hour.

Finally, closed, shut and open, in contrast with other closed-scale adjectives, are not subject to hedging modification, as illustrated in (57). This correlates with the greater resistance to a process sense for the related verbs, as in (58).
a. \# The door was fairly shut/pretty open.
b. The tank was fairly full/pretty empty.
c. The room was pretty dark/fairly quiet.

a. \# The door opened/closed for a few seconds. (event duration reading) cf. The door was opening/closing for a few seconds.

The correlations are summarized in the table below.

\begin{tabular}{|l|c|c|c|}
\hline & scale & process sense & $\boldsymbol{x}$ is $\boldsymbol{A}$ \\
\hline darken & closed & $\checkmark$ & non-maximal \\
\hline dry, clear & closed & $(?)$ & flexibly maximal \\
\hline fill & closed & $?$ & flexibly maximal \\
\hline empty & closed & $(\#)$ & $\begin{array}{c}\text { strictly maximal, } \\
\text { takes fairly }\end{array}$ \\
\hline close, shut & closed & $\#$ & $\begin{array}{c}\text { strictly maximal, } \\
\text { resists fairly }\end{array}$ \\
\hline
\end{tabular}

\subsection{Resistance to accomplishment senses}

Just as closed-scale verbs differ in taking process senses readily, so do open-scale verbs differ in taking accomplishment senses. Verbs like widen and deepen lack accomplishment senses, as illustrated in $(59 \mathrm{a}, \mathrm{b})$. As Hay et al. point out, this correlates with the ill-formedness of proportional modification as in (59c). Other examples in this group are The signal weakened, The shoot lengthened, The smoke thinned, and so on. The open-scale verb cool, which takes an accomplishment sense, is illustrated in (60) for comparison.

(59) a. The gap widened in ten minutes $\nrightarrow$ The gap was widening throughout those ten minutes.

b. The gap widened in ten minutes but it was still narrow.

c. \# The gap is half-wide/completely wide. 
(60) a. The soup cooled in ten minutes $\rightarrow$ The soup was cooling throughout those ten minutes.

b. ! The soup cooled in ten minutes but it was still hot.

c. The soup is half-cool/completely cool.

I have argued that the telos of a deadjectival accomplishment is the onset of the standard endstate, denoted by $x$ is A. I have also argued that where adjectives associated with open scales are modified by endpoint-oriented adverbs, the adverb is interpreted with reference to the lower bound of the relevant property-that is, the least degree of the property that counts as A in evaluating $x$ is $A$. In section 3.2 I proposed that where completely modifies an open-scale adjective such as cool, the modifier is interpreted as 'indubitably, definitely, unquestionably'. For example, The soup is completely cool is interpreted as 'The soup is definitely/unquestionably cool'. Correspondingly, The soup cooled completely is interpreted as 'The soup cooled all the way to being (definitely) cool'. Discussing resultatives in section 3.6, I argued that modifiers such as half and almost with open-scale adjectives are interpreted with reference to the lower bound of the standard value of the relevant property. So, for example, at the end of the event denoted by Jeroen talked himself half drowsy Jeroen was not in fact drowsy, but was in a state halfway to drowsiness. What all these analyses have in common is that the interpretation targets the lower bound of the standard value of the relevant property, as diagrammed in (61).

(61) a. The soup cooled in ten minutes.

The soup cooled completely.

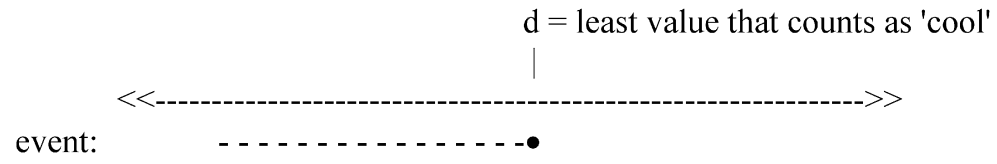

b. Jeroen talked himself half-drowsy.

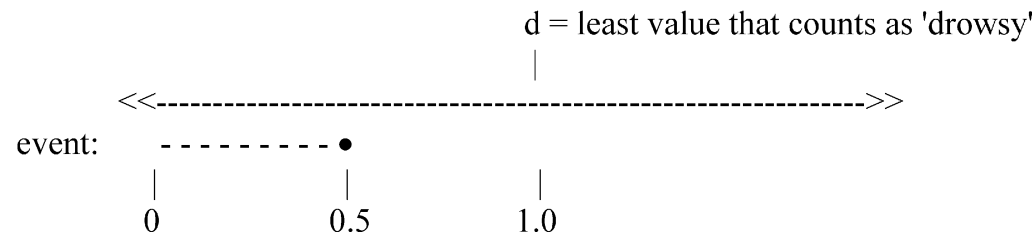

As in Hay et al.'s account, the availability of proportional modification is expected to correlate with the availability of accomplishment senses. However, I claim that with open-scale verbs and adjectives the correlation is not mediated by the lack of an upper bound to the property scale, but by some characteristic of the standard value of the property, in particular the lower bound of the standard value. The targeting of the lower bound, or least value that counts as A, rather than a 
maximal value of the relevant property, is particularly evident with almost, given that $x$ is almost $A$ entails ' $\mathrm{x}$ is not A'. Other liminal modifiers are illustrated in (62). The modifiers in (62a-d) signal a value falling short of the minimal value that counts as $A$, while the modifiers in (62e-f) signal a value that is minimally within the standard value.
a. \# The gap is almost wide.
b. \# The gap is not quite wide.
c. \# The hole is almost deep.
d. \# The hole is not quite deep.
e. \# The gap is only just wide.
f. \# The hole is only just deep.

Note that the examples in (62) are somewhat more acceptable if the adjective is interpreted as 'too A' or 'A enough'; for example, (62a) is improved if understood to mean 'The gap is almost too wide/almost wide enough'. But the modified values 'too wide' and 'wide enough' are not interpreted according to the contextual standard value for wide, but are really implicit comparatives, and not relevant to the issue at hand. For example, The gap is almost too wide means something like 'The gap has a width of $n$ metres, where $n$ is almost $n^{*}$, and $n *$ is a width too great for the current purpose'. The implicit comparison is between the actual width of the gap and a specific width determined by the context, but there is no commitment to either measurement falling within the contextual standard for $x$ is wide. Similarly, there is no contradiction in The gap is very wide but not wide enough.

The situation with resultatives is less clear. In (44) above (section 3.6) I cited Vanden Wyngaerd's examples for thin, repeated in (63).
a. The joggers ran the pavement thin.
b. \# The joggers ran the pavement entirely/almost/half thin.
c. \# The pavements were entirely/almost/half thin.

Given the correlations demonstrated so far, we would expect an adjective to take both the resultative construction and proportional modifiers, or neither, but this is not the case for thin, as (63a) is an attested resultative. I have no explanation for this inconsistency here, but I note that wide and deep are slightly odd as complements to become, suggesting that they may fail to provide an adequate telos.

a. ? The gap became wide (in a month).

b. ? The hole became deep (in a few minutes).

In some resultative constructions, however, wide and deep are more natural, as illustrated in (65).
a. He slashed the gap wide.
b. He dug the hole deep.

A possible explanation for the acceptability of (65) may be that they are not true resultatives, but 'false' or 'adverbial' resultatives (see Mateu (2002:89-92) for discussion). One sign of adverbial resultatives is that the result phrase may be replaced with an adverb, as in (66a). This is possible for deep in (66b), but still slightly odd for wide in (63c), to my judgment. 
(66) a. He tied his shoelaces tight/tightly.

b. He dug the hole deeply.

c. (?) He slashed the gap widely.

Another characteristic of adverbial resultatives is that they are only based on transitive verbs, and the direct object is a selected argument of the verb. This is a possible interpretation of the collocations slash gap and dig hole, as in (67), where the verbs are used as verbs of creation, rather than as verbs of caused change of state.

a. He slashed a gap (in the hedge).

b. He dug a hole.

However, this may not be the intended sense of the verbs used in the resultative construction, as shown in the examples in (68), where the event involves a pre-existing gap or hole.

a. John found the gap in the hedge. He slashed the gap wide.

b. John found the hole in the path. He dug the hole deep.

Nevertheless, even in these examples the creation of a new entity, rather than the change of a property in an existing entity, can be understood, as illustrated in (69). The point in these examples is that the wide gap or deep hole which results from enlarging the existing gap or hole can be referred to as a new entity, replacing the old entity. The examples in (68) can be paraphrased as in (69). ${ }^{18}$

(69) a. Where the narrow gap was in the hedge, John slashed a wide gap.

b. Where the small hole was in the path, John dug a deep hole.

The creation sense of the verbs in (67) and (69) contrasts with other transitive verb resultatives, as shown below. Neither (70b) nor (70c) is a reasonable inference from (70a). In contrast, (70e,f) are reasonable inferences from $(70 \mathrm{~d})$.
a. John hammered the disc flat.
b. John made the disc by hammering.
c. Where the convex disc was, John hammered a flat disc.
d. John dug the hole deep.
e. John made the hole by digging.
f. Where the (small) hole was, John dug a deep hole.

Although a full exploration of this phenomenon would exceed the bounds of this paper, I conclude tentatively that the acceptable resultatives with wide and deep may not be canonical resultatives, in that they do not simply depict a single theme undergoing a caused change of state in the property associated with the resultative phrase adjective. Rather, they may depict the

\footnotetext{
${ }^{18}$ The same pattern appears with paint, which is a verb of creation where the direct object refers to a created image. We may understand (i) below to denote an event in which John paints a picture which shows a white fence. Suppose John paints a brown fence and then decides to change the colour to white. Note that this situation can equally be described by (i), in terms of affecting an existing object, or as in (ii), in terms of replacing an existing object with another, distinct object.

(i) John painted the fence white.

(ii) Where the brown fence was, John painted a white fence.
} 
coming into existence of a new entity which bears the stated property, in place of the old entity. If this is so, then the event structure may be provided by the gradual coming into existence of the new entity, which is an incremental theme. If so, the event structure is not mapped from a change in the property associated with the resultative phrase adjective. If this is correct, then the acceptable resultatives with wide and deep are not relevant to the present discussion.

To return to the main point of this section, I have argued that the telos of an accomplishment verb associated with an open property scale and the target of modification by proportional adverbs is the least degree of the relevant property that counts as A, as illustrated in (71).

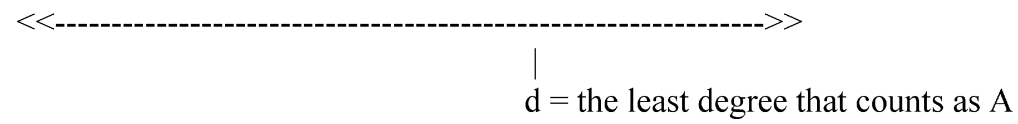

For some open-scale verbs and their corresponding adjectives, such as wide/widen and deep/ deepen, the boundary between 'not A' and ' $\mathrm{A}$ ' is apparently not accessible for the interpretation of proportional modifiers and accomplishment verbs. It appears that the standard value for adjectives like wide and deep is in some contexts insufficiently determined. I do not have a full account of why this is so, and leave this to further research. ${ }^{19}$ The point remains, however,

\footnotetext{
intransitive verbs; see section 3.3.) Feature (dirty/wet) antonyms).

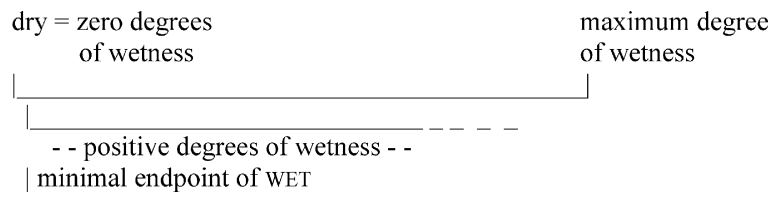

${ }^{19}$ My claim that the lower bound of the standard value is involved with verbs that fail to provide a telos is consistent with observations in Wechsler (2005, in press) concerning resultatives. Wechsler argues that in a resultative like hammer the metal flat the result phrase must be headed by a closed-scale gradable adjective, and that the bound on the closed property scale provides the telos of the event. He includes an account of the contrast in acceptability of resultatives like wipe it clean/dry vs. *wipe it dirty/wet. (The wet/dirty adjectives fall outside my main discussion because they have no associated

Wechsler points out that antonym pairs like wet/dry are associated with a particular scale structure, as I have illustrated in (i) below (Rusiecki (1985) also discusses these adjectives as Absence of Feature (clean/dry) and Presence of

Dry expresses an extreme value which is the complete absence of wetness, and all other degrees on the scale are positive degrees of wetness. Accordingly, Wechsler observes that adjectives like wet are minimal endpoint adjectives, and their scales have a lower bound. Wechsler shows that the default standard value for certain closed-scale adjectives is the maximal value (e.g. dry, clean, empty), and implicitly generalises this observation to an assumption that a bound at either end of a property scale (maximum or minimum) will normally supply a default standard value for the adjective, and thus we would expect the minimal value to supply a standard for wet and dirty. However, as Wechsler points out, the standard values for wet and dirty are not normally determined by the minimal values of wetness and dirtiness, but rather by some contextually determined norm (for example, one small spot of dirt on the cuff does not normally justify calling a shirt dirty). Given that the minimal inherent standard is ignored in determining the actual standard, Wechsler concludes that wet/dirty adjectives are 'de facto open-class' adjectives. Given his proposed generalisation that certain resultatives require closed-scale adjectives, Wechsler argues that the contrast between wipe it clean and *wipe it dirty is explained by analysing wet/dirty as open-scale adjectives. In support of his claim that wet/dirty are open-scale, Wechsler points out that these adjectives resist modification with almost: *The towel is almost wet/dirty; cf. my (62) below.

I agree with Wechsler that the standard value of wet/dirty adjectives is normally not determined by the minimal value. I consider that this reflects some indeterminacy in the lower bound of the standard value (as I claim is also the case for wide). In turn, the indeterminacy of the lower bound of the standard value may be related to the unacceptability of 
that the observed phenomena do not arise with a proposed maximal value for wide and deep, but with the lower bound of the standard value denoted by $x$ is wide/deep. This is consistent with the position argued for in this paper, that (assuming a telos or an anchor for proportional modifiers is available for open-scale verbs and adjectives) it is calculated from the standard value of the property, not the maximal value.

To sum up this section so far: I have shown that differences among the standard values of the relevant property predict the availability of process and accomplishment readings for deadjectival verbs. The observed tendencies are along the same lines as the basic correlation claimed by Hay et al., in that process-resistant verbs have closed scales, and accomplishmentresistant verbs have open scales. However, the three-way division summarized in the table below is best predicted by the standard value of the property denoted by $x$ is $A$, rather than by the open or closed nature of the property scale.

\begin{tabular}{|l|c|c|}
\hline verb aspect & standard value: denotation of $x$ is $A$ & property scale \\
\hline $\begin{array}{l}\text { default } \\
\text { accomplishment }\end{array}$ & $\begin{array}{c}\text { maximal state } \\
\text { determinate lower bound }\end{array}$ & closed \\
\hline free variation & $\begin{array}{c}\text { non-maximal state } \\
\text { determinate lower bound }\end{array}$ & closed or open \\
\hline process only & indeterminate lower bound & open \\
\hline
\end{tabular}

resultatives like *wipe it dirty, though I take no position on the determinants of acceptability in resultatives: I merely claim in section 3.3 that given an acceptable resultative, the endstate of the event is the standard value of the property and need not be maximal.

I do not agree with Wechsler that the wipe it dry/*wet contrast follows from the difference between closed and open scales. For one thing, despite their odd minimal values, the wet/dirty adjectives still have maximal values, as in The towel was totally/completely wet/dirty. Note that completely and totally here are oriented to the upper bound, and The towel was completely wet does entail 'The towel could not have been wetter'. According to the usual usage of the term closed scale to mean 'a scale with an upper (maximal) bound', wet and dirty are closed scale adjectives. In fact wet, dirty, dry, and clean are all adjectives associated with upper bounds, therefore are all closed scale adjectives, and Wechsler's analysis does not account for the contrasts among them. An account in terms of the lower bound of the standard value, without reference to the closed or open nature of the scale, might provide a more successful account.

Finally, I comment on an example Wechsler cites in support of his claim that wet/dirty are open-class adjectives. Wechsler points out that Kenny's entailment goes through for the related verbs, as in (ii).

John is wetting the towel $\rightarrow$ John has wetted the towel

(As I explained in section 3.3, I have avoided transitive deadjectival verbs in the main discussion of this paper because the actions of the agent may contribute to event aspect, in which case the data may not bear on the aspect of the theme's change of state.) The issue I address here is the entailed state of the towel: assuming the truth of 'John has wetted the towel', does it follow that the towel is wet?

John has wetted the towel but it isn't wet.

Given the more normal, non-minimal standard value for wet, (iii) is non-contradictory. But there is also a stricter interpretation available, based on the inherent minimal standard, on which (iii) is contradictory, and 'John has wetted the towel' does entail 'The towel is wet'. On the second interpretation, I suggest that Kenny's entailment is not indicative of an atelic predicate, but of an accomplishment predicate (roughly 'make the towel wet') which is instantaneously realised. Compare also 'Look out! You're dirtying the floor!' which would normally commit the speaker to the truth of 'Now the floor's dirty'. 


\subsection{The telic implicature}

As stated above, I assume that the 'become A-er' sense is basic, and is included in the accomplishment interpretation, given that the accomplishment sense of a deadjectival verb entails the 'become A-er' sense. The accomplishment sense, then, consists of the 'become A-er' sense augmented by some further content, provided by implicature.

I propose that the content of the implicature is ' $\mathrm{x}$ becomes A', rather than '( $\mathrm{x}$ verbs) completely' or 'x becomes maximally A'. I claim that the strength of the implicature co-varies with the ease of identifying the telos, which is the final transition to the state in which the theme bears the property to the standard degree. The telos is more or less easily identified according to the accessibility to modification of the lower bound of the state.

With adjectives such as empty, the maximal state denoted by $x$ is $A$ is fully specified as, for example, the absence of contents. The criterion for determining such a state holds fairly constant across contexts. Verbs corresponding to these adjectives carry the 'become A' implicature most strongly.

With adjectives such as cool the state denoted by $x$ is $A$ may vary not only with respect to normative values for the theme (cf. cool beer, cool soup), but also with respect to background presuppositions concerning the reason for the judgment, as discussed in section 3.7. Similar considerations apply to The room darkened or The room quietened. The telos for these verbs is less easily identified than that for verbs of the empty type, and verbs like cool and darken vary quite freely between process and accomplishment senses.

Finally, as discussed in section 4.3, with adjectives like wide and narrow the states denoted by $x$ is $A$ have indeterminate lower bounds which are not accessible to threshold modifiers such as only just, not quite, and almost. Here a satisfactory telos for an accomplishment reading is not identifiable, and these verbs have only the process reading.

\subsection{The 'become A-er' sense is basic to deadjectival verb senses}

I concur with Hay et al.'s central assumptions that (i) the basic sense of a deadjectival verb is the sense Hay et al. identify as atelic, and which I gloss as 'become A-er', and (ii) the telic interpretation of a deadjectival verb arises by implicature. Accordingly, alternating deadjectival verbs are not semantically ambiguous. However, some further consideration of assumptions (i) and (ii) is warranted, as we have just seen that certain deadjectival verbs such as empty have default accomplishment senses, and apparently resist process interpretations. The claim that the 'become A-er' sense is basic might appear inconsistent with these verbs, as we might expect all deadjectival verbs to show the claimed basic interpretation in at least some contexts.

This section identifies an interaction between the position of rate adverbs such as quickly and the aspectual interpretation of the modified predicate. It is shown that postverbal quickly, which tends to produce a process reading for alternating predicates, also produces a process reading with default accomplishment deadjectival verbs.

Predicates modified by quickly can differ in telicity, depending on the position of the adverb. ${ }^{20}$ Preverbal quickly forces a telic reading if one is available, while postverbal quickly

\footnotetext{
${ }^{20}$ I am grateful to Stefan Engelberg (personal communication) for bringing the quickly alternation to my attention.
} 
allows both a telic and atelic reading. ${ }^{21}$ As a working hypothesis, it appears that preverbal quickly expresses the quick completion of the event, thus requiring a bounded event, and postverbal quickly modifies the rate of the event's unfolding. ${ }^{22}$ The latter interpretation, roughly a 'manner' interpretation, is compatible with either a bounded or an unbounded event. This is illustrated in (72a), where the completion of the event can be denied. Contrast this with (72b) where the denial of completion of the event is contradictory.

(72) a. John ate the apple quickly, but Mary snatched it away before he finished it. b. ! John quickly ate the apple, but Mary snatched it away before he finished it.

The process reading with postverbal quickly allows a for adverbial, as in (73).

(73) John ate the apple quickly for a minute (but he found a worm and threw the rest away).

Note that eat does not really lexicalise a telos, which is indirectly provided by the specified extent of the incremental theme, the apple. But if a verb lexicalises the telos, postverbal quickly cannot force a process reading. ${ }^{23}$ A continuation cancelling the telos is contradictory, as in (74)-(75).

! John died quickly, but they managed to save him at the last minute. cf. John was dying quickly, but they managed to save him at the last minute.

! The disease killed John quickly, but the new treatment saved him. cf. The disease was killing John quickly, but the new treatment saved him.

\footnotetext{
${ }^{21}$ A full account of this phenomenon would go beyond the bounds of the present paper, and will be given in work in preparation.

${ }^{22}$ This is not the same distinction as that identified by Travis (1988:292), for the examples shown below (her (29a-d)).
}

(i) Quickly John will be arrested by the police.

(ii) John quickly will be arrested by the police.

(iii) John will be quickly arrested by the police.

(iv) John will be arrested quickly by the police.

Travis claims that quickly modifies the event of the arrest in (i) and (ii), but modifies the process of the arrest in (iii) and (iv). Although the distinction between process and event appears similar to the distinction I draw, Travis gives the same interpretation for preverbal and postverbal quickly in (iii) and (iv), and doesn't explicitly discuss telicity.

${ }^{23}$ Wickboldt (2000:364-367) proposes that postverbal adverbs 'suspend telicity', not in the sense that the telos is no longer entailed, but in the sense that 'subevents of the described event are made accessible for further commentary' (p. 364). I consider that her examples shown below illustrate differences in advancing or not advancing the reference time of the narrative (normally correlated with (a)telicity). In (i) and (ii), the postverbal adverb focuses on the process of die, and the past tense of died fails to move the reference time forward. Further narration on the process is appropriate as in (i), but presupposing a moved-forward reference time is anomalous, as in (ii), cf. (iii).

(i) John died quickly. He gasped once and was gone.

(ii) \# John died quickly. At the reading of the will, his children were furious.

(iii) John died last year. At the reading of the will, his children were furious.

This is not the same contrast as the actual telicity shift I show. As Wickboldt points out, all of (i)-(iii) entail that John was dead. 
Davidson's (1967) analysis of adverbs as predicates on events was chiefly motivated by the need to capture entailments such as that from John died quickly to John died. ${ }^{24}$ If we assume that entailments of this form are valid, then we must accept that John ate the apple quickly also entails John ate the apple. If so, then neither John ate the apple quickly nor John ate the apple entails that the telos was reached, and presumably the telic interpretation is an implicature. The implicated telos can be suspended in eat the apple, but the lexicalized telos in die cannot be suspended. $^{25,26}$

The quickly alternation can cast further light on the possible senses of deadjectival verbs. Verbs with only the 'become A-er' interpretation, such as increase and widen, alternate between the achievement and process senses, as illustrated in (76). With preverbal quickly, as in (76a,c), the natural interpretation is of a completed change, with the for adverbial giving the duration of the result state. Post-verbal quickly, as in $(76 \mathrm{~b}, \mathrm{~d})$, produces the process reading with the for adverbial modifying the duration of the process.
a. The price quickly increased (for a week).
b. The price increased quickly (for a week).
c. The gap quickly widened (for a day).
d. The gap widened quickly (for a day).

Verbs like cool and darken alternate fairly freely between the process and accomplishment senses, and quickly modification sharpens the contrast between them. The accomplishment

\footnotetext{
${ }^{24}$ The entailment is considered valid for manner adverbs, including quickly, but not for adverbs such as apparently or allegedly. See Parsons (1990) for discussion of adverb entailments.

25 Explicitly, the telos cannot be suspended in the non-progressive.

26 The quickly phenomenon is slightly complicated with verbs of translocation, where a time-point modification may focus on the onset or endpoint of the event. Taylor (1988) points out that come and go denoting durative journeys are modifiable by time-point adverbials, but with different interpretations, as illustrated below.
}

(i) John went home (from work) at 8.00 .

(ii) John came home (from work) at 8.00 .

In (i) we understand that John left work at 8.00, but in (ii) that he arrived home at 8.00 , despite the fact that the same spatial journey is reported. The effect does not entirely depend on explicitly orientational verbs such as come and go, and may be contextual. A co-worker saying John drove home at 8.00 will be understood to mean that he left work at 8.00 , but if his wife says the same thing she will be understood to mean that he arrived home at 8.00. The point which bears on the present discussion is that the go interpretation, with departure focus, does not entail completion of the journey: cf. (iii) and (iv) below.

(iii) John went home at 8.00 , but he never got there

(iv) ! John came home at 8.00 , but he never got here.

In a neutral context, most verbs of translocation are interpreted like go, and can be interpreted as reporting only a departure. So in (v) below, preverbal quickly need not force the entailment that John reached the store, only that he promptly departed for the store, despite the fact that the predicate drive/run/walk to the store does lexicalize the telos.

(v) ? John quickly drove/ran/walked to the store (but they caught him halfway). 
reading is additionally signalled by the entailment of the standard endstate, as illustrated in $(77) .^{27}$
a. The solution quickly cooled (! but it was still quite hot when I checked it).
b. The solution cooled quickly (but it was still quite hot when I checked it).
c. The sky quickly darkened (! but it was still quite light when we left).
d. The sky darkened quickly (but it was still quite light when we left).

As with increase and widen, a for adverbial with preverbal quickly is interpreted as the duration of a result state (78a), and with postverbal quickly is interpreted as the duration of a process (78b).
a. The weather quickly cooled for an hour.
b. The weather cooled quickly for an hour.

Verbs like dry and clear, which lexicalize a maximal value, also alternate between process and accomplishment senses with quickly.
a. ! The clothes quickly dried, but were still quite damp when I checked them.
b. The clothes dried quickly, but were still quite damp when I checked them.
c. The sky quickly cleared for an hour. for as result state
d. The sky cleared quickly for an hour. for as process duration

Verbs like empty, fill and close, which otherwise resist a process interpretation (to varying extents), also alternate with quickly.
a. ! The tank quickly filled, but John was able to block the inflow pipe before it was half-full.
b. The tank filled quickly, but John was able to block the inflow pipe before it was half-full.
a. ! The tank quickly emptied, but we managed to block the leak before it was half-empty.
b. The tank emptied quickly, but we managed to block the leak before it was half-empty.

\footnotetext{
(i) The solution slowly cooled (? but it was still quite hot when I checked it).

(ii) The solution cooled slowly (and it was still quite hot when I checked it).

(iii) The sky slowly darkened (? but it was still quite light when we left).

(iv) The sky darkened slowly (and it was still quite light when we left).

(v) The solution gradually cooled (? but it was still quite hot when I checked it).

(vi) The solution cooled gradually (and it was still quite hot when I checked it).

(vii) The sky gradually darkened (? but it was still quite light when we left).

(viii) The sky darkened gradually (and it was still quite light when we left).
}

${ }^{27}$ Although quickly seems to produce the sharpest contrast, adverb position also makes a difference with slowly and gradually, as illustrated below. The main difference is that postverbal slowly and gradually, in contrast to quickly, introduce the expectation that the states 'cool' and 'dark' were not reached, so the continuation takes and rather than but. 
a. ! The door quickly closed, and John just managed to get his foot in.

b. The door closed quickly, and John just managed to get his foot in.

The process sense with postverbal quickly can take a for adverbial modifying the duration of the process, as in (83).

\section{The tank filled/emptied quickly for a few minutes (but then the flow dwindled} to a trickle).

The contrast between process and accomplishment readings is also shown by the interpretation of again. With a telic change-of-state predicate, again has the restitutive sense that the event restores the theme to a state it was in previously. This sense appears with telic fill and preverbal quickly in (84a), which entails that the tank had been full previously. With a process, however, again denotes only resumption of the process, as in (84b), which does not entail that the tank had been full previously.

a. The tank quickly filled again after we cleaned the filter.

b. The tank filled quickly again after we cleaned the filter.

I conclude that all deadjectival verbs in principle have process senses. More accurately, all deadjectival verbs have the 'become A-er' sense, and this sense is interpreted as a process (of iterated achievement-like transitions) with a duration adverbial. The accomplishment sense is derived by the implicature ' $\mathrm{x}$ becomes $\mathrm{A}$ ' as proposed in section 4.4.

\section{Conclusion}

I have defended the traditional distinction between the two main senses of deadjectival verbs, glossed as 'become A-er' and 'become A'. In particular, I have argued that the telos of an event denoted by a deadjectival verb on the accomplishment reading is the onset of the standard endstate, the state denoted by $x$ is $A$. The standard telos theory gives a simple unified account of three types of verb.

(i) Verbs like dry, clear, and empty are associated with closed property scales. The telos of such verbs on an accomplishment reading is the onset of the maximal state corresponding to the upper bound of the property scale. However, with these verbs the standard value of the property (the value that counts as 'A') is the maximal value, and the standard telos theory subsumes these verbs without any need to appeal to the notion of traversing the property scale to its upper limit.

(ii) Verbs like darken, quieten, and ripen are also associated with closed scales, but the telos of a denoted event on an accomplishment reading is not the onset of the maximal state corresponding to the upper bound of the scale. Instead, it is the onset of the state denoted by $x$ is $A$, as predicted by the standard telos theory.

(iii) Verbs like cool are associated with open scales, but have accomplishment readings. The telos for these verbs is again the onset of the state denoted by $x$ is $A$.

I have also shown that the standard value of the property (the value that counts as ' $A$ '), rather than the closed or open nature of the property scale, predicts the availability of process and accomplishment senses for deadjectival verbs. 
I have argued that proportional modifiers such as completely, half, and almost have different interpretations modifying open-scale and closed-scale expressions. Modifying a closed-scale expression, a proportional modifier is oriented to the upper bound of the property scale. Modifying an open-scale expression, a proportional modifier is oriented to the lower bound of the standard value for the property. Consequently, the acceptability of a proportional modifier is not diagnostic of a closed scale associated with the modified expression.

I have proposed that the telic implicature with deadjectival verbs is assigned the content 'become A', rather than 'completely' giving the interpretation ' $x$ becomes maximally A'. With this change, (i) the interpretation of the implicature is given by the standard value of the property, not by the closed or open structure of the property scale, and (ii) the strength of the implicature correlates with characteristics of the standard value-specifically, whether or not the standard value has an accessible lower bound to provide a telos for the derived verb. In short, the structure of the property scale need not be directly appealed to in the interpretation of deadjectival change-of-state verbs.

In proposing that the telos for deadjectival accomplishments is provided by the onset of the state denoted by $x$ is $A$, I also correlate the contextual and collocational influences on accomplishment senses with the contextual and collocational factors generally acknowledged to be involved in calculating the standard value denoted by $x$ is $A$. Consequently, there is no need to propose contextual variability in the closed and open structure of property scales.

\section{Acknowledgements}

I wish to thank Beth Levin and Jen Hay for discussion of some of the issues addressed here during the preparation of this work. I also wish to thank an anonymous referee for Lingua, whose comments and observations have helped me to improve this paper. Any remaining errors or infelicities are entirely my own.

\section{References}

Abusch, D., 1986. Verbs of Change, Causation and Time. Report No CSLI-86-50. Centre for the Study of Language and Information (CSLI), Stanford University.

Bertinetto, P.M., Squartini, M., 1995. An attempt at defining the class of "gradual completion verbs". In: Bertinetto, P.M., Bianchi, V., Higginbotham, J., Squartini, M. (Eds.), Temporal Reference, Aspect and Actionality. Vol. 1: Semantic and Syntactic Perspectives. Rosenberg and Sellier, Torino, Italy, pp. 11-26.

Davidson, D., 1967. The logical form of action sentences. In: Rescher, N. (Ed.), The Logic of Decision and Action. University of Pittsburgh Press, Pittsburch, pp. 81-120.

Dowty, D., 1979. Word Meaning and Montague Grammar. Reidel, Dordrecht.

Dowty, D., 1991. Thematic proto-roles and argument selection. Language 67, 547-619.

Filip, H., 1999. Aspect, Eventuality Types and Nominal Reference. Garland, New York and London.

Grice, H.P., 1975. Logic and conversation. In: Cole, P., Morgan, J.L. (Eds.), Speech Acts. Academic Press, New York, pp. 41-58. Reprinted in Davis, S. (Ed.), 1991. Pragmatics: A Reader. Oxford University Press, Oxford, pp. 113127.

Hay, J., 1998. The non-uniformity of degree achievements. Paper presented to the LSA, January 1998.

Hay, J., Kennedy, C., Levin, B., 1999. Scalar structure underlies telicity in “degree achievements”. In: Matthews, T., Strolovitch, D. (Eds.), Proceedings of SALT IX. Cornell University, Ithaca, NY, pp. 127-144.

Horn, L., 1984. Toward a new taxonomy for pragmatic inference: Q-based and R-based implicature. In: Schiffrin, D. (Ed.), Meaning, Form and Use in Context: Linguistic Applications (Georgetown University Round Table on Languages and Linguistics 1984). Georgetown University Press, Washington, DC, pp. 11-42.

Jackendoff, R., 1996. The proper treatment of measuring out, telicity, and perhaps even quantification in English. Natural Language and Linguistic Theory 14, 305-354. 
Kennedy, C., 1999. Projecting the Adjective: The Syntax and Semantics of Gradability and Comparison. Garland, New York.

Kennedy, C., McNally, L., 1999. From event structure to scale structure: degree modification in deverbal adjectives. In: Matthews, T., Strolovitch, D. (Eds.), Proceedings of SALT IX. Cornell University, Ithaca, NY, pp. 163-180.

Kenny, A., 1963. Action, Emotion and Will. Routledge and Kegan Paul, London.

Levin, B., 2000. Aspect, lexical semantic representation, and argument expression. In Proceedings of the Berkeley Linguistic Society 26 (BLS 26).

Levin, B., Rappaport Hovav, M., 1991. Wiping the slate clean: a lexical semantic exploration. In: Levin, B., Pinker, S. (Eds.), Lexical and Conceptual Semantics. Elsevier, Amsterdam, (special issue of Cognition), pp. 123-151.

Levin, B., Rappaport Hovav, M., 1995. Unaccusativity: At the Syntax-Lexical Semantics Interface. MIT Press, Cambridge, MA.

Mateu Fontanals, Jaume, 2002. Why can't we wipe the slate clean? A lexical-syntactic approach to resultative constructions. Catalan Working Papers in Linguistics 8, 71-95.

Paradis, C., 2001. Adjectives and boundedness. Cognitive Linguistics 12, 47-65.

Parsons, T., 1990. Events in the Semantics of English. MIT Press, Cambridge, MA.

Piñón, C., 1997. Achievements in an event semantics. In: Lawson, A. (Ed.), Proceedings from Semantics and Linguistic Theory VII (SALT VII). Cornell University, Ithaca, NY, pp. 276-293.

Piñón, C., 1999. Durative adverbials for result states. In: Bird, S., Carnie, A., Haugen, J., Norquest, P. (Eds.), WCCFL 18 Proceedings. Cascadilla Press, Somerville, MA, pp. 420-433.

Pustejovsky, J., 1995. The Generative Lexicon. MIT Press, Cambridge, MA.

Rothstein, S., 2004. Structuring Events. Blackwell, Oxford.

Rusiecki, J., 1985. Adjectives and Comparison in English: A Semantic Study. Longman, Essex, UK.

Taylor, K.A., 1988. We've got you coming and going. Linguistics and Philosophy 11, 493-513.

Travis, L., 1988. The syntax of adverbs. McGill working papers in linguistics: Special issue on comparative Germanic syntax. McGill University, Montreal, pp. 280-310.

Vendler, Z., 1967. Linguistics in Philosophy. Cornell University Press, Ithaca, NY.

Wechsler, S., 1995. The Semantic Basis of Argument Structure. CSLI, Stanford, CA.

Wechsler, S., 2005. Weighing in on scales: a reply to Goldberg and Jackendoff. Language 81, 465-473.

Wechsler, S., in press. Resultatives under the 'event-argument homomorphism' model of telicity. In: Erteschik-Shir, N., Rapoport, T. (Eds.), The Syntax of Aspect: Deriving Thematic and Aspectual Interpretation. Oxford University Press.

Wickboldt, J.M., 2000. Some effects of manner adverbials on meaning. In: Tenny, C., Pustejovsky, J. (Eds.), Events as Grammatical Objects. CSLI, Stanford, CA, pp. 359-371.

Vanden Wyngaerd, G., 2001. Measuring events. Language 77, 61-90. 